REVISTA DE DERECHO UNED, NÚM. 17, 2015

\title{
LA LIMITACIÓN DE MANDATOS PARLAMENTARIOS: UNA TÉCNICA CONSTITUCIONAL PARA LA RENOVACIÓN PERMANENTE DE LAS ÉLITES POLÍTICAS
}

\section{LEGISLATIVE TERM LIMITS: A CONSTITUTIONAL TECHNIQUE FOR PERMANENT RENOVATION OF POLITICAL ELITES}

\author{
ANTONIO IBÁÑEZ-MaCÍAS \\ Profesor Contratado Doctor de Derecho Constitucional \\ Universidad de Cádiz
}

Resumen: En este trabajo estudiamos la limitación de mandatos parlamentarios en Estados Unidos y en Méjico, con el propósito de analizar la problemática de su establecimiento, sus ventajas o efectos positivos, y, en su caso, cómo paliar sus inconvenientes o efectos negativos. Asimismo se estudian las dificultades técnico-jurídicas y políticas de su regulación, pensando en una hipotética implantación en España. A tal propósito, a lo largo de la obra se realizan propuestas concretas.

Abstract: In this work, the legislative term limits in USA and Mexico are studied in order to analyze the problems of its establishment, its advantages and positive effects, and, where appropriate, how to overcome their disadvantages or negative effects. Technical and legal and political difficulties of their regulation, considering a hypothetical implementation in Spain, are also studied. For this purpose, specific proposals are the work along made.

Palabras clave: Limitación de mandatos, limitación de mandatos parlamentarios, técnica constitucional, élites políticas, renovación.

(C) UNED. Revista de Derecho UNED, núm. 17, 2015 
Keywords: Term limits, legislative term limits, constitutional technique, political elites, renovation,

Recepción original: 8/07/2013

Aceptación original: 1/09/2015

Sumario: I. Introducción. II. Breve referencia a la limitación de mandatos parlamentarios en Estados Unidos y en Méjico. II.1. En Estados Unidos. II.2. En México. III. Ventajas o efectos positivos de la limitación de mandatos. III.1. Cuestiones preliminares. III.2. El mayor reparto del poder político. III.3. Algunas propuestas al respecto. III.4. La renovación permanente de las élites políticas. III.5. Algunas propuestas al respecto. III.6. La prevención contra la aparición de redes clientelares y de prácticas corruptas. IV. Posibles inconvenientes o efectos negativos y cómo paliarlos. IV.1. Una cuestión preliminar: la refutación de algunas objeciones teóricas y prácticas. IV.2. La inexperiencia de los parlamentarios y sus consecuencias negativas. IV.3. Posibles soluciones a la inexperiencia de los parlamentarios y a la debilidad del parlamento frente al gobierno. IV.4. Otro posible inconveniente: se impone una visión cortoplacista de la política. IV.5. El problema de la rendición de cuentas. V. Obstáculos jurídicos y políticos para el establecimiento de la limitación de mandatos. V.1. Obstáculos jurídicos: el derecho de sufragio. V.2. Obstáculos políticos: la tendencia general de los gobernantes a perpetuarse en el ejercicio del poder. VI. A modo de conclusión. Sobre la eficacia de la limitación de mandatos.

\section{INTRODUCCIÓN}

La limitación de mandatos es una restricción legal o constitucional al tiempo que una persona puede ocupar un determinado cargo público de carácter electivo. Esta técnica prohíbe que la persona afectada por la limitación de mandatos pueda presentarse a la reelección para determinado cargo público. De ahí que, en algunas latitudes, como en Méjico, la limitación de mandatos reciba el nombre de «prohibición de reelección» o de "principio de no reelección».

La limitación de mandatos puede ser consecutiva (aunque también podemos llamarla relativa), cuando prohíbe que una persona ocupe un determinado cargo durante dos o más mandatos consecutivos. Transcurrido un tiempo (normalmente un mandato de por medio) la persona afectada puede volver a presentarse a la reelección, aplicándosele nuevamente la limitación de mandatos. Y así sucesivamente. También puede ser absoluta cuando se impone no de forma 
consecutiva, sino de por vida (se prohíbe que una persona pueda ser reelegida para un cargo electivo transcurrido un determinado número de mandatos o de años en el ejercicio del cargo público).

En teoría, la limitación de mandatos puede ser, a su vez, parcial (para un determinado cargo público electivo) o total (para todos los cargos públicos electivos). Es decir, en este último caso se prohíbe que una persona que haya transcurrido un tiempo en el ejercicio de determinado cargo público electivo pueda ocupar ningún otro cargo electivo, aunque sea de naturaleza distinta. En el Derecho constitucional comparado la limitación de mandatos ha sido hasta ahora parcial.

La limitación de mandatos es una técnica que puede inscribirse perfectamente en el pensamiento constitucionalista tendente a limitar el poder político del Estado para garantizar los derechos y libertades de la sociedad civil. Puede obedecer a diversos fines, según la naturaleza del cargo al que se aplique. Cuando se aplica a los miembros del poder ejecutivo, en especial al Presidente de la República en el régimen presidencial, su finalidad básica es evitar una deriva autoritaria del propio régimen político, que ponga en peligro las libertades civiles y políticas y la democracia constitucional misma. Tampoco hay que descartar otros fines secundarios, como prevenir la acumulación de ventajas y privilegios que la permanencia en un cargo público electivo puede conllevar.

Cuando se aplica a miembros del poder legislativo, su finalidad principal es distribuir el poder político entre los ciudadanos y evitar que la permanencia en el cargo por mucho tiempo de los legisladores cree una clase política profesionalizada y privilegiada ${ }^{1}$, alejada de las demandas de los ciudadanos, y propensa a caer en determinadas formas de clientelismo y/o corrupción política.

En cambio, cuando la limitación de mandatos se aplica a los miembros de determinados organismos públicos de control, tengan carácter jurisdiccional o no (Tribunales Constitucionales, Tribunales de Cuentas, Defensores del Pueblo, etc.) su finalidad es garantizar la independencia e imparcialidad de tales organismos frente a los órganos políticos que los han designado, ante las indebidas influencias que las perspectivas de reelección pueden ocasionar en los miembros de los organismos de control ${ }^{2}$.

\footnotetext{
${ }^{1}$ Para el concepto de clase política, véase mosca, GaEtano; La clase Política, Fondo de Cultura Económica, México, 2004.

${ }^{2}$ Véase MAGIDE HERRERO, Mariano. Límites constitucionales de las administraciones independientes, Ministerio de Administraciones Públicas, Madrid, pág. 99.
} 
La limitación de mandatos suele tener por objeto cargos públicos electivos, pero en ocasiones se aplica a los órganos directivos de los partidos políticos ${ }^{3}$, y no hay ningún motivo aparente que impida la extensión de esta medida, de igual manera, a los órganos directivos de los sindicatos ${ }^{4} \mathrm{y}$ de las organizaciones empresariales ${ }^{5}$.

De las distintas formas que puede adoptar la limitación de mandatos por razón del cargo electivo objeto de la misma, en este trabajo nos hemos centrado en la limitación de mandatos parlamentarios. Esta institución tiene precedentes en nuestro Constitucionalismo histórico, en especial en la Constitución de Cádiz de 1812, cuyo artículo 110 dispuso que «los diputados no podrán volver a ser reelegidos, sino mediando otra diputación». Este precepto recibió su influencia de la Constitución francesa de 1791, la cual estableció que: «los miembros del Cuerpo legislativo podrán ser reelegidos en la siguiente legislatura y no podrán volver a serlo más que después de un intervalo de una legislatura (art. 6 de la Sección III del Capítulo primero del Título III). Estos precedentes se dieron en la etapa del constituciona-

\footnotetext{
${ }^{3}$ Respecto del PSOE, véase la Disposición adicional quinta de los Estatutos probados en el 38..$^{\circ}$ Congreso Federal celebrado en febrero de 2012. Puede verse en: http://www.psoe.es/source-media/000000515500/000000515572.pdf. (Visitada el 23 de junio de 2014).

Respecto de Izquierda Unida, véase el artículo 16 de los Estatutos aprobados por la VIII Asamblea Federal Extraordinaria de IU, de 10, 11 y 12 de diciembre de 2004. Puede verse en: http://www.izquierda-unida.es/sites/default/files/doc/Estatutos_VIII_ AsambleaFederalExtraordinaria_10_11_12_Diciembre_2004.pdf (Visitada el 23 de junio de 2014).

Respecto de Unión Progreso y Democracia, véase artículo 23.2 de las Resoluciones del Segundo Congreso. Ponencia de organización y Estatutos, celebrado en Madrid, del 1 al 3 de noviembre de 2013. Puede verse en: http://www.upyd.es/fckupload/ pdf/6_Organizacion\%20y\%20estatutos.pdf (Visitada el 23 de junio de 2014).

${ }^{4}$ Por ejemplo, el art.32, letra g), de los Estatutos del sindicato Comisiones Obreras, aprobados en el 9. ${ }^{\circ}$ Congreso Confederal, en Madrid, los días 17, 18, 19 y 20 de diciembre de 2008, dispone que: «El secretario o secretaria general no podrá ser elegido por más de tres mandatos». Véase: http://www.ccoo.es/comunes/estatico/CSCCOO/documentos/estatutos.pdf. (Visitada el 23 de junio de 2014).

Por su parte, los Estatutos de la Unión General de Trabajadores, aprobados en el 41. ${ }^{\circ}$ Congreso Confederal, aprobados en Madrid, del 10 al 13 de abril de 2013, disponen en el artículo 40.3 que «a partir del 41 Congreso Confederal la persona que ostente la Secretaría General no podrá ser reelegida por más de tres mandatos consecutivos». Pueden verse en: http://portal.ugt.org/ugtpordentro/estatutos_confederales_UGT_41_ congreso.pdf (Visitada el 23 de junio de 2014).

${ }^{5}$ Los Estatutos de la Conferencia Española de Organizaciones Empresariales, aprobados por la Asamblea General el 15 de noviembre de 2006, no establecen límites de mandato para sus órganos directivos. Pueden verse en: http://www.ceoe.es/resources/image/estatutos_ceoe_2006.pdf (Visitada el 23 de junio de 2014).
} 
lismo revolucionario ${ }^{6}$ y no volvieron a repetirse en constituciones posteriores.

Sin embargo, no se realiza en este trabajo un estudio del establecimiento de esta institución en nuestro constitucionalismo histórico (o en el francés) ni de los motivos por la que fue abandonada en Constituciones posteriores. Tampoco hemos realizado un estudio histórico más amplio, del surgimiento de la limitación de mandatos, o rotación de cargos, en la Historia de las ideas y de las instituciones políticas y de su evolución hasta nuestros días ${ }^{7}$.

Nos hemos centrado en el estudio de la limitación de mandatos parlamentarios en la época actual. De los cuatro países que actualmente cuentan con esta institución en alguno de sus niveles territoriales de gobierno (Estados Unidos, Méjico, Costa Rica y Filipinas ${ }^{8}$ ), hemos estudiado los dos primeros casos, con el propósito de analizar la problemática de su establecimiento, sus ventajas o efectos positivos, sus inconvenientes o efectos negativos y, en su caso, cómo paliar-

${ }^{6}$ VARELA SUANZES inscribe ambas Constituciones, la francesa de 1791 y la española de 1812, en la misma etapa histórica del constitucionalismo revolucionario.VALERA SUANZES, Joaquín (Ed.). Textos básicos de la Historia Constitucional Comparada, Centro de Estudios Políticos y Constitucionales, Madrid, 1998, pág. XXII.

${ }^{7}$ Una aproximación histórica a las limitaciones de mandato puede verse en PETRACCA, Mark P. «Rotation in Office: The history of an idea», en Gerald, Benjamin and Michel J. MALBIN Limiting Legislative Terms, Congresional Quarterly Press, Washington, DC., 1992.

${ }^{8}$ Las Constituciones de Costa Rica y Filipinas establecen una limitación consecutiva de mandatos parlamentarios. La Constitución Política de la República de Costa Rica, de 7 de noviembre de 1949, dispone en su artículo 107, dentro de la organización de la Asamblea Legislativa, que: «Los diputados durarán en sus cargos cuatro años y no podrán ser reelectos en forma sucesiva». Puede verse en: http://www.asamblea.go.cr/Documents/Constituci\%C3\%B3n\%20Pol\%C3\%ADtica.pdf. (Visitada el 23 de junio de 2014).

La Constitución de la República de Filipinas, de 1987, prevé una limitación sucesiva de mandatos tanto para el Senado como para la Cámara de Representantes. Respecto del Senado se establece que: «The term of office of the Senators shall be six years and shall commence, unless otherwise provided by law, at noon on the thirtieth day of June next following their election. No Senator shall serve for more than two consecutive terms. Voluntary renunciation of the office for any length of time shall not be considered as an interruption in the continuity of his service for the full term of which he was elected» (Art. VI, Sección 4). Y respecto de la Cámara de Representantes se prevé: «The Members of the House of Representatives shall be elected for a term of three years which shall begin, unless otherwise provided by law, at noon on the thirtieth day of June next following their election. No Member of the House of Representatives shall serve for more than three consecutive terms. Voluntary renunciation of the office for any length of time shall not be considered as an interruption in the continuity of his service for the full term for which he was elected» (Art. VI, Sección 7). Puede verse en: http://www.wipo.int/edocs/lexdocs/laws/en/ph/ph020en. pdf (Visitada el 23 de junio de 2014). 
los, así como las dificultades técnico-jurídicas y políticas de su regulación. Todo ello de cara a una futura e hipotética implantación en España. A tal propósito, a lo largo de la obra se realizan propuestas concretas.

\section{BREVE REFERENCIA A LA LIMITACIÓN DE MANDATOS PARLAMENTARIOS EN ESTADOS UNIDOS Y EN MÉJICO}

\section{II.1. En Estados Unidos}

De acuerdo con la US Term limits (USTL), asociación que lidera el movimiento por la implantación de las limitaciones de mandatos en Estados Unidos, la limitación de mandatos es el movimiento de base más grande en las historia de los Estados Unidos 9 .

A similar conclusión llegan autores que se han dedicado al tema, de forma que se considera que pocos actos en la reciente historia política han creado el mismo nivel de implicación popular directa que las limitaciones de mandato ${ }^{10}$; siendo considerado uno de los acontecimientos políticos más importantes en Estados Unidos en mucho tiempo ${ }^{11}$; o como el cambio institucional más significativo, e incluso drástico, en el gobiernos estatales federados en las dos últimas décadas ${ }^{12}$.

No obstante, el debate sobre las limitaciones de mandato en Estados Unidos se remonta a sus orígenes fundacionales. La Sección V de los Artículos de la Confederación limitaba la representación en el Congreso a «tres años en seis» ${ }^{13}$. Según PETRACCA, desde 1777, siete estados limitaron el número de mandatos de los cargos ejecutivos, y varios estados (Pensilvania, Delaware, New York, y Virginia) establecieron algún tipo de límite sobre los parlamentarios o requisitos para su rotación en el cargo. Por otra parte, seis estados- Delaware,

\footnotetext{
${ }^{9}$ http://termlimits.org/about/ (Página visitada el 3 de marzo de 2014).

${ }^{10}$ CARESS, Stanley M. and KUNIOKA, Todd T. Term limits and Their Consequences: The Aftermath of Legislative Reform, Ithaca, NY, USA: State University of New York Press, 2012, pág. 18.

${ }^{11}$ CRANE, Edward H. and PILON, Roger (Eds.). The politics and Laws of term limits, Washington: The Cato Institute, 1994, pág. 3.

${ }^{12}$ KURTZ, Karl T.; CAIN, Bruce E.; NIEMI, Richard G. (Eds.). Institutional Change in American Politics: The Case of Term limits, Ann Arbor, MI, USA: University of Michigan Press, 2009, 185.

${ }^{13}$ La Sección V de Los Artículos disponía, "No state shall be represented in Congress by less than two, nor by more than seven members; and no person shall be capable of being a delegate for more than three years in any term of six years».
} 
Maryland, New Jersey, New York, Pennsylvania, y Carolina del Sur limitaron los mandatos de algunos cargos locales. ${ }^{14}$

La idea de limitaciones de mandato para los miembros del Congreso fue propuesta y debatida durante la Convención constitucional (fue una idea defendida por los anti-federalistas) pero no fue incluida finalmente en la Constitución de 1787. PETRACCA opina que a pesar del silencio constitucional sobre la materia, a lo largo del siglo XIX la rotación en el cargo permaneció como un principio popular de gobierno republicano, un principio con considerables efectos prácticos. Observa que hasta 1901 los miembros de la Cámara de representantes no superan los dos mandatos en el cargo (es decir, cuatro años). Hoy un tercio de la Cámara de representantes está compuesto por miembros que han ocupado el cargo durante 14 años o más. Esta tendencia hacia el "profesionalismo» en política empieza a darse en el siglo $\mathrm{XX}^{15}$.

En 1948 se aprobó la enmienda número 22 a la Constitución de los Estados Unidos, que limita a dos mandatos completos la duración máxima en el cargo de Presidente de la República ${ }^{16}$. Sin embargo, según CARESS y KUNIOKA, el esfuerzo moderno por crear límites de mandato para el Congreso de Estados Unidos y para los legisladores estatales es relativamente reciente y puede ser datado hacia 1988, cuando el partido republicano nacional aprobó esa medida para su plataforma de partido. En cambio, el partido demócrata, predominante en la Cámara de Representantes, veía las limitaciones como un método potencial para desalojarlo del poder ${ }^{17}$.

No obstante, mientras que las iniciativas populares sobre las limitaciones de mandatos aprobadas en 1990 en California, Colorado y Oklahoma parece que han sido dirigidas por activistas locales, la mayoría

${ }^{14}$ PETRACCA, Mark P. "Rotation in Office: The history of an idea», op. cit. en KURTZ, Karl T.; CAIN, Bruce E.; NIEMI, Richard G. (Eds.). Institutional Change in American Politics: The Case of Term limits, op. cit. pág. 10.

${ }^{15}$ Véase PETRACCA, Mark P. "The Poison of Professional Politics», en Policy Analysis, Cato Institute, Núm. 51 (May 10), 1991, http://www.cato.org/pubs/pas/pa151.html; en el mismo sentido, SWAIN, Jhon W., Stephen BORRELLI, BRIAN C. REED, and SEAN F., EVANS. "A New Look at Turnover in the U. S. Howse of Representatives, 1789-1998», American Politics Quarterly, Núm. 23, 2000, págs. 435-57, cit. en KURTZ, Karl T.; CAIN, Bruce E.; NIEMI, Richard G. (Eds.). Institutional Change in American Politics: The Case of Term limits, op. cit. pág. 10.

${ }^{16}$ Sobre la limitación del mandato del Presidente de la República en la Historia americana, véase KORZI, Michael J. Presidential Term limits in American History: Power, Principles and Politics, Texas A\&M University Press, College Station, TX, USA, 2011.

${ }^{17}$ CARESS, Stanley M. and KUNIOKA, Todd T. Term limits and Their Consequence..., op. cit. págs. 27 ss. 
de las iniciativas sobre el mismo asunto promulgadas desde 1992 ha sido promovida por una organización nacional, la U.S. Term limits ${ }^{18}$.

Casi todas las propuestas de «term limits» entre 1990 y 1995 establecen tales limitaciones en el Congreso nacional y en los parlamentos estatales. Al final de 1994, 20 estados habían limitado los mandatos del Congreso, y 21 estados habían limitado los mandatos de los parlamentos estatales.

Pero en 1995 los límites de mandato del Congreso son declarados inconstitucionales por el Tribunal Supremo Federal (Caso U. S. Term limits, Inc. v. Thornton, 514 U. S, 779). La Corte declara que los estados no pueden poner límites sobre los requisitos para el acceso a un cargo federal ${ }^{19}$.

De los 21 estados que inicialmente aprobaron limitaciones de mandatos para sus respectivos parlamentos, en cuatro -Massachusetts, Oregón, Washington y Wyoming- los tribunales supremos estatales las rechazaron. En tres de estos estados (salvo Oregón), en los que los límites de mandato fueron establecidos vía iniciativa legislativa popular, los tribunales supremos estatales declararon que las limitaciones de mandato constituían un requisito adicional para los cargos públicos y que, como tales, sólo podían ser establecidas por la Constitución y no por las leyes. Ninguno de estos estados tiene un procedimiento para enmendar la Constitución mediante iniciativa popular. En Oregón, el Tribunal Supremo resolvió un asunto diferente: una iniciativa popular no puede contener más de una materia.

En otros dos estados, en Idaho y en Utah, los parlamentos estatales rechazaron las limitaciones de mandato, pues éstas fueron establecidas por ley y no mediante reforma constitucional, de modo que los parlamentos pudieron rechazarlas sin votación popular.

De acuerdo con la US Term limits (USTL), a fecha de hoy los límites de mandato permanecen en 15 estados de los Estados Unidos, en sus parlamentos estatales. Además, ocho de las diez ciudades más grandes de Estados Unidos han adoptado limitaciones de mandato para sus ayuntamientos y/o alcaldes, y otros 37 estados han decidido poner límites a los mandatos de diversos cargos constitucionales ${ }^{20}$.

${ }^{18}$ RAUSCH, John David JR. «Understanding the Term Limits Movement», en Rick FARMER, John David RAUSCH Jr., and John C. GREEN (Eds.), The Test of Time: Coping with Legislative Term limits, Lexington Books, Lanham, MD, 2003, pág. 230.

${ }^{19}$ KURTZ, Karl T.; CAIN, Bruce E.; NIEMI, Richard G. (Eds.). Institutional Change in American Politics..., op. cit. pág. 11.

${ }^{20} \mathrm{http} / / /$ termlimits.org/about/ (Página visitada 3 de marzo de 2014). 
Conforme a los datos aportados por el Conferencia Nacional de Parlamentos Estatales (NCSL) ${ }^{21}$, los 15 estados en los que se ha adoptado la limitación de mandatos, por fecha de puesta en práctica de la medida, son los siguientes:

De los 15 estados $^{22}$, tres aprobaron la medida en 1990 (California, Colorado y Oklahoma), ocho en 1992 (Arkansas, Michigan, Florida, Ohio, Dakota del Sur, Montana, Arizona y Misuri), uno en 1993 (Maine), otro en 1995 (Luisiana), otro en 1996 (Nevada). Finalmente, Nebraska aprobó la limitación de mandatos en el año 2000.

De esos 15 estados, la limitación de mandatos es absoluta o de por vida en seis, y es consecutiva en nueve. Tienen una limitación absoluta de mandatos: Arizona y Michigan (en ambos estados el límite es de seis años para los diputados y ocho para los senadores); Misuri, donde el límite es de ocho años tanto para diputados como para senadores; Nevada, donde el límite es de doce años tanto para la asamblea como para el senado; California y Oklahoma: en este último estado existe un límite total de doce años. El tiempo total puede ser dividido entre las dos cámaras, o acumulado enteramente en una de las cámaras. En California, antes de 2012, sus límites de mandato eran los mismos de Oklahoma; a partir de ese año, son idénticos a los de Arkansas: seis años para la asamblea y cuatro para el senado.

En cambio, la limitación de mandatos es consecutiva en los siguientes estados: Nebraska, donde el límite es de ocho años en total; Arizona, Colorado, Florida, Maine, Montana, Ohio y Dakota del Sur: en estos estados el límite es de ocho años tanto para los diputados como para los senadores; y por último Luisiana, donde el límite es de doce años para cada una de las cámaras.

La razón por la que la limitación de mandatos no se ha extendido a más estados de los Estados Unidos es muy sencilla ${ }^{23}$ : la inmensa mayoría de los estados que tienen limitaciones de mandatos (salvo, como veremos, una sola excepción), las ha establecido a través del proceso de iniciativa popular llevada a referéndum, y no a petición de los propios parlamentarios, contra cuyos intereses se establece la li-

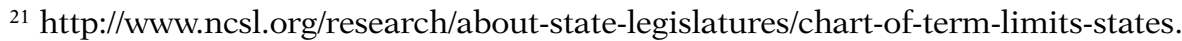
aspx. Datos actualizados a enero de 2013. (Página visitada el 3 de marzo de 2014).

${ }^{22}$ Las disposiciones constitucionales y legislativas de estos estados, sobre la limitación de mandatos, pueden verse en: http://www.ncsl.org/research/about-state-legislatures/term-limits-provisions-state-law-and-constitutions.aspx (Página visitada el 9 de abril de 2014).

${ }^{23}$ La explicación puede encontrarse en: http://www.ncsl.org/research/about-statelegislatures/frequently-asked-questions-about-term-limits.aspx (Consultada el 3 de marzo de 2014). (Página escrita por Karl KURTZ). 
mitación de mandatos. Ahora bien, sólo 24 estados federados disponen de la institución de la iniciativa popular, y casi todos ellos ya han adoptado la limitación de mandatos o bien las han derogado o votado en contra de la misma.

De esos 24 estados que cuentan con la institución de la iniciativa popular, dos (Alaska e Illinois) nunca han votado límites de mandato para los parlamentarios, debido a que su procedimiento de iniciativa popular incluye restricciones que impiden que una medida de este tipo sea llevada a votación popular. Otros dos estados (Misisipi y Dakota del Norte) han votado límites de mandato para sus legisladores en el pasado, pero las medidas no han prosperado en la votación popular.

En los estados que no disponen de la institución de la iniciativa popular, se requeriría de un acto del propio parlamento para establecer las limitaciones de mandato. Esto ha ocurrido sólo dos veces: el parlamento de Luisiana votó para autoimponerse los límites de mandato en 1995. También el parlamento de Utah votó en 1994 en el mismo sentido, pero en este caso el propósito de la votación era evitar el triunfo de una iniciativa popular sobre la limitación de mandatos que era más restrictiva para los parlamentarios. Finalmente, en el año 2002, el parlamento de Utah derogó sus límites de mandato.

En definitiva, en la inmensa mayoría de los estados afectados la limitación de mandatos no se ha establecido como consecuencia de la voluntad de los propios parlamentarios, sino que ha sido impuesta por un movimiento popular de base de democracia directa.

A diferencia de los movimientos de masas, en los que se involucran un gran número de personas para tratar de influir en los cargos y políticos electos, en un movimiento de base de democracia directa son unos pocos activistas los que tratan de recoger un número de firmas para llevar un asunto a votación popular, con independencia de lo que opinen los cargos electos. Es imprescindible para la existencia de este tipo de movimiento de base que la Constitución establezca institutos de democracia semidirecta (como la iniciativa popular y el referéndum), que permitan intervenir directamente a los ciudadanos en los asuntos públicos, incluso contra la voluntad de los cargos públicos electos ${ }^{24}$. Estos institutos fueron introducidos a nivel estatal a finales del siglo XIX y principios del siglo XX, como reivindicación de grupos populares de base, para someter a control popular los órganos

${ }^{24}$ La diferencia entre movimiento de masas y movimiento de base de democracia directa puede verse en CARESS, Stanley M. and KUNIOKA, Todd T. Term limits and Their Consequence..., op. cit. págs. 18 ss. 
legislativos estatales, acusados de corrupción y de favorecer exclusivamente a determinados intereses monetarios y a los trusts ${ }^{25}$.

Sin embargo, aunque casi la práctica totalidad de las limitaciones de mandato ha sido establecida mediante iniciativa popular, la regulación de esta institución de democracia semidirecta varía mucho de un estado a otro, de modo que sus efectos sobre los límites de mandato son también muy diferentes. Por ejemplo, importa mucho que la iniciativa popular sea da carácter legislativo o constitucional, pues la primera en muchos casos puede ser modificada o rechazada por el parlamento estatal. En cambio, la segunda es mucho más difícil de modificar.

Sólo 16 estados disponen de iniciativa ciudadana de reforma constitucional. Catorce de los quince estados que mantienen la limitación de mandatos adoptaron esta medida mediante una reforma constitucional de iniciativa popular. Esto constituye, por un lado, una garantía para el mantenimiento de los límites de mandato en dichos estados, pero, por otro lado, una gran barrera para su expansión a otros estados, que no disponen de la mencionada institución de democracia semidirecta $^{26}$.

\section{II.2. En México}

En el caso de Méjico, como ha dicho ANAYA ${ }^{27}$,

«Con mayor énfasis que otros regímenes políticos, en el mexicano, el tema genérico de la reelección ha sido tratado en forma muy apasionada. Ha sido objeto de amplios debates y profundas divisiones políticas prácticamente desde las pugnas entre Benito Juárez y el amplio grupo de políticos liberales con los que combatió la intervención francesa (1865-1872). (...) No hay duda que estas importantes etapas de nuestra historia, la República restaurada y el porfiriato, han marcado profundamente nuestro imaginario popular contemporáneo. Han producido que en la reflexión del tema se confundan las implicaciones concernientes a la reelección del Poder Ejecutivo con las del Legislativo.»

${ }^{25}$ CRONIN, T.. Direct Democracy: the politics of initiative, referéndum and recall, Harvard University Press., 1989, pág. 45.

${ }^{26}$ En este sentido, CARESS, Stanley M. and KUNIOKA, Todd T. Term limits and Their Consequence..., op. cit. pág. 3. ${ }^{\circ}$

${ }^{27}$ ANAYA, Luis «Experiencias políticas e imaginarios sociales sobre la reelección en México, 1928-1964. La transformación de un derecho ciudadano en un principio político y en un tabú social», Hmex, LIV, 1, 2004, págs. 365-403, esp. pág. 366.

(C) UNED. Revista de Derecho UNED, núm. 17, 2015 
En consecuencia, es preciso diferenciar el tema de la reelección del poder ejecutivo respecto de la del poder legislativo. A esta última dedicamos este epígrafe.

En Méjico, la limitación de mandatos parlamentarios se introdujo, como consecutiva, mediante reforma constitucional de 1933 a la Constitución de 1917, y se ha modificado mediante reforma constitucional de febrero de 2014, incluyendo una modalidad absoluta muy laxa. Como modalidad consecutiva, ha estado vigente, por tanto, más de 80 años.

Como hemos visto en la introducción, la limitación de mandatos parlamentarios consecutiva tiene como precedentes la Constitución francesa de 1791 y la Constitución española de 1812. Asimismo, en el Decreto Constitucional para la Libertad de la América Mexicana, expedido en Apatzingán en 1814, se estipulaba que «tampoco serán reelegidos los diputados, sino es que medie el tiempo de una diputación ${ }^{28}$.

Sin embargo, a partir de la Constitución de 1824 no volverá a establecerse la limitación de mandatos de los parlamentarios. Tampoco se estableció inicialmente en la Constitución de 1917, sino que se introdujo en virtud de la reforma de 1933.

En efecto, la Constitución de 1917 prohibió la reelección del poder ejecutivo pero permitió la de diputados y senadores. El artículo 83 del texto original de la Constitución de 1917 disponía que «el Presidente entrará a ejercer su encargo el $1 .^{\circ}$ de diciembre, durará en él cuatro años, y nunca podrá ser reelecto ${ }^{29}$.

Si buscamos las causas de la reforma de 1933, algún autor ${ }^{30}$ la ve en una previa reforma constitucional, la de 1928, que modificó el artículo 83 de la Constitución, permitiendo la reelección, aunque no inmediata, del Poder Ejecutivo ${ }^{31}$.

${ }^{28}$ Sobre estos antecedentes puede verse: MARTÍNEZ BÁEZ, Antonio. «Un debate en pie. Historia del reeleccionismo», Obras politico-constitucionales, vol. I, México, UNAM, 1994, págs. 397-400; JAIMES DELGADO, David Alberto. «¿Cómo fortalecer el poder legislativo federal en México? El caso de la reelección inmediata de los miembros del Congreso", Cuestiones Constitucionales, núm.25, julio-diciembre 2011, págs. 59-99, esp. págs. 60-61.

${ }^{29}$ Diario Oficial, Órgano del Gobierno Provisional de la República Mexicana, Mé-

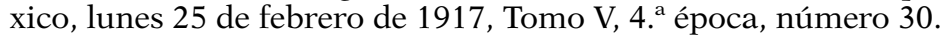

${ }^{30}$ ANAYA, Luis. «Experiencias políticas e imaginarios sociales...», op. cit. pág. 368.

${ }^{31}$ La reforma de 24 de enero de 1928 disponía que: «Artículo 83. El Presidente entrará a ejercer su cargo el primero de diciembre; durará en él seis años y nunca podrá ser reelegido para el período inmediato». 
La reforma de 1928 tenía como destinatario al general Álvaro Obregón, pero éste «fue asesinado por el fuego de un fanático cristino» ${ }^{32}$. Como consecuencia de este hecho, la reforma de 1933 suprime toda posibilidad de reelección del Presidente y de los gobernadores, y prohíbe la reelección «inmediata» de los diputados y senadores, mediante la modificación de los artículos 51, 55, 56. 58. 59, 83, 84, 85 y 115 de la Constitución.

La duración del mandato de la Cámara de los Diputados pasa de dos a tres años, y la de los Senadores, de cuatro a seis años (arts. 51 y 56). Los Senadores y Diputados al Congreso de la Unión no podrán ser reelectos para el período inmediato (art. 59). El Presidente entrará a ejercer su encargo el $1 .^{\circ}$ de diciembre y durará en él seis años. El ciudadano que hay desempeñado el cargo de Presidente de la República, electo popularmente, con el carácter de interino, provisional o sustituto, en ningún caso y por ningún motivo, podrá volver a desempeñar ese puesto (art. 83). Esta limitación de mandatos absoluta se extiende a los gobernadores de los Estados, que no podrán durar en su cargo más de cuatro años (art. 115. II)

El art 115 prohíbe la reelección, para el período inmediato, a «los presidentes municipales, regidores y síndicos de los ayuntamientos, electos popularmente por elección directa». La misma medida se aplica a los diputados de las legislaturas de los Estados (art. 115. III).

Con la prohibición absoluta de reelección presidencial se cerraba el paso a todo intento de perpetuarse en el poder por parte del ejecutivo. ¿Pero por qué se incluyó la prohibición de reelección inmediata de los legisladores?

La razón puede hallarse en un intento de centralizar el poder del Partido Nacional Revolucionario $\left(\mathrm{PNR}^{33}\right)$ a nivel nacional, frente a los líderes y partidos locales que integraban esa gran coalición. Y al mismo tiempo fortalecer, de ese modo, al Poder Ejecutivo frente al Legislativo.

En efecto, después de la revolución y la Constitución de 1917 se produjo una dispersión del poder en el país. De modo que «los jefes políticos de los estados manipulaban los procesos electorales para diputados y senadores, y enviaban a las Cámaras a sus cercanos como representantes de sus intereses. El Congreso posrevolucionario era un

${ }^{32}$ ANAYA, Luis. «Experiencias políticas e imaginarios sociales...», op. cit. pág. 371.

${ }^{33}$ El Partido Nacional Revolucionario (PNR) empezó a denominarse Partido de la Revolución Mexicana (PRM) a partir de 1938, y Partido Revolucionario Institucional (PRI) desde 1946. 
espacio de disputa entre las fracciones políticas en el que las fuerzas locales se agrupaban y se expresaban ${ }^{34}$.

Para centralizar el poder en el partido, los dirigentes nacionales del PNR promovieron la no elección consecutiva para ambas cámaras legislativas y otros cargos (gobernadores y presidentes municipales) en una Convención extraordinaria del partido en 1932, medida que fue aprobada después por el Congreso Federal en 1933. «La consecuencia inmediata de esta reforma electoral permitió a Lázaro Cárdenas, el primer candidato presidencial del PNR, intervenir directa y decisivamente en la nominación de las listas de candidatos para diputados y senadores de su partido en las elecciones de 1934, iniciando lo que más tarde se llamaría «el patronazgo presidencial»» ${ }^{35}$.

La doctrina señala como principales efectos de la reforma constitucional de 1933 los siguientes:

Primero, una renovación de los líderes políticos, mediante «la incorporación de nuevos cuadros políticos al PNR. Con ello, se incrementó la capacidad del partido para cooptar movimientos sociales y organizaciones políticas emergentes. La rotación de cargos permitió a la dirigencia nacional del PNR llevar a cabo la política de «puertas abiertas», a fin de incorporar movimientos y asociaciones que se gestaban independientemente del partido» ${ }^{36}$.

Segundo, la centralización del poder en el Comité Ejecutivo Nacional del PNR frente a los líderes y partidos locales que lo integraban. El fortalecimiento de la organización nacional del PNR se debe básicamente a que el partido pasó a ser

«una pieza central en las estrategias de los políticos locales para continuar y avanzar en sus carreras (...) Para realizar sus ambiciones -moldeadas por el nuevo marco institucional-, los políticos locales empezaron a depender enteramente de la organización nacional del partido, que se convirtió en el principal regulador del acceso a una

${ }^{34}$ CORTEZ SALINAS, Josafat. «La propuesta de la reelección inmediata de legisladores en la reforma del estado de 2010", Boletín Mexicano de Derecho Comparado, Nueva Serie, Año XLIV, núm. 132, septiembre-diciembre de 2011, págs. 1321-1333, esp. pág. 1323.

${ }^{35}$ TOVAR MENDOZA, Jesús. «Condicionantes políticos que impiden la reelección de legisladores en México», Convergencia. Revista de Ciencias Sociales, vol. 17, núm. 52, enero-abril de 2010, págs. 187-205, esp. pág. 189. Artículo disponible en: http:// www.redalyc.org/articulo.oa?id=10512246008.

${ }^{36}$ NACIF, Benito. La no reelección consecutiva y la persistencia del partido hegemónico en la Cámara de Diputados en México, Centro de Investigación y Docencia Económicas, Documento de Trabajo núm. 63, México, pág. 7. En el mismo sentido, ANAYA, Luis. «Experiencias políticas e imaginarios sociales...», op. cit. pág. 377, JAIMES DELGADO, David Alberto. “¿Cómo fortalecer ...?», op. cit. pág. 63. 
gran variedad de cargos de elección en constante rotación en los gobiernos municipales, estatales y federal $»^{37}$.

Tercero, el debilitamiento del poder legislativo e incluso su sometimiento al poder ejecutivo, en especial al Presidente de la República, el cual decidirá, en el seno del PNR, la lista de candidatos a diputados y senadores, y demás cargos públicos electivos, es decir, determinará la carrera política de los candidatos ${ }^{38}$. Como pone de manifiesto COSío, «el porvenir de un diputado no depende en absoluto de los ciudadanos de su respectivo distrito electoral, sino del favor de los dirigentes del Partido y, en última instancia, de la voluntad del Presidente». ${ }^{39}$

Cuarto, se inhibe la formación de partidos de la oposición. Esto se debe a combinación de varios factores: el comportamiento de la mayoría de los partidos de la oposición como partidos de notables, el sistema electoral de mayoría relativa en distritos uninominales y la prohibición de reelección consecutiva. En efecto, en un sistema electoral mayoritario, en distritos uninominales, la mayoría de los partidos de la oposición no eran más que agrupaciones en torno a candidatos individuales o grupos de candidatos,

«surgían al aproximarse las elecciones y desaparecían cuando sus promotores fracasaban en obtener el cargo. En los pocos casos en los que candidatos independientes conseguían llegar a la Cámara de Diputados, la imposibilidad de reelegirse acababa con su independencia o con sus carreras políticas (...) Competir por un puesto en el Congreso valía la pena sólo como parte de una estrategia de promoción política de largo plazo y esto era algo que los partidos de oposición no podían ofrecer. Los partidos de oposición disponían de muy pocos incentivos para reclutar políticos que compitieran por puestos de elección». ${ }^{40}$

Estos factores impedían el desarrollo de la carrera política fuera del PRI, lo que, unido a la política de puertas abiertas de este partido, llevaba a consolidar su hegemonía política.

${ }^{37}$ NACIF, Benito. La no reelección consecutiva..., op. cit. págs. 8 y 9; en el mismo sentido, WELDON, Jeffrey A. «El Congreso, las maquinarias políticas locales y el 'maximato': las reformas no-reeleccionistas de 1933», en DWORAK, Fernando (coord.), El legislador a examen. El debate sobre la reelección legislativa en México, México, FCE-Cámara de Diputados, 2003, págs. 33-53, citado por CORTEZ SALINAS, Josafat. «La propuesta de la reelección inmediata...», op. cit. pág.1324.

${ }^{38}$ Véase nota anterior.

${ }^{39}$ COSÍO, Daniel. El sistema político mexicano, México, Joaquín Mortiz, 1972, pág. 29, citado por CORTEZ SALINAS, Josafat. «La propuesta de la reelección inmediata...», op. cit. pág.1323.

${ }^{40}$ NACIF, Benito. La no reelección consecutiva..., op. cit. págs. 11 y 21. 
Sin embargo, parece que el factor determinante de la deficiente representación de los partidos de la oposición en el parlamento federal fue el sistema electoral, y no tanto el principio de prohibición de la reelección consecutiva. Pues tan pronto se pasó a un sistema electoral progresivamente más proporcional, el PRI fue perdiendo su hegemonía política, hasta incluso pasar a la oposición, y todo ello a pesar de que se siguió manteniendo el principio de no reelección consecutiva de los legisladores. Como ha dicho TOVAR, «las diversas ampliaciones del sistema de representación proporcional en 1971, 1977 y 1986 lograron extender significativamente las fracciones parlamentarias de la oposición hasta tal punto que el partido de gobierno perdió su tradicional mayoría parlamentaria en $1998 »^{41}$.

El sistema electoral vigente para la elección de los diputados y senadores es mixto, en parte proporcional y en parte mayoritario, aunque predominan claramente los parlamentarios elegidos por sistema electoral mayoritario. El 60 por ciento de los diputados son elegidos por sistema electoral mayoritario y el 40 por ciento por sistema electoral proporcional en circunscripciones regionales. El 75 por ciento de los senadores son elegidos por sistema electoral mayoritario y el 25 por ciento por sistema electoral proporcional en una sola circunscripción nacional ${ }^{42}$.

Para la elección de los diputados por sistema electoral mayoritario, la fórmula empleada es la de mayoría relativa. En cambio, en el Senado, dos senadores de cada entidad federativa son designados por el sistema de mayoría relativa y el tercer senador se asigna a la «primera minoría», entendiendo por tal la candidatura del segundo partido más votado en la circunscripción (Artículo 14.3 de la LGIPE).

En la elección de diputados y senadores por sistema electoral proporcional se sigue la misma fórmula del resto mayor (Artículos 16 y 21 de la LGIPE). Sin embargo, para la elección de los diputados por sistema electoral proporcional se establece una barrera electoral del

${ }^{41}$ TOVAR MENDOZA, Jesús. «Condicionantes políticos...», op. cit. pág. 190.

${ }^{42}$ En efecto, como dispone la Ley General de Instituciones y Procedimientos Electorales (en adelante, LGIPE), «La Cámara de Diputados se integra por 300 diputados electos según el principio de votación mayoritaria relativa, mediante el sistema de distritos electorales uninominales, y 200 diputados que serán electos según el principio de representación proporcional, mediante el sistema de listas regionales votadas en circunscripciones plurinominales» (art. 14.1). «La Cámara de Senadores se integrará por 128 senadores, de los cuales, en cada Estado y en el Distrito Federal, dos serán electos según el principio de votación mayoritaria relativa y uno será asignado a la primera minoría. Los 32 senadores restantes serán elegidos por el principio de representación proporcional, votados en una sola circunscripción plurinominal nacional (art. 14.2). 
tres por ciento (art. 15.2 de la LGIPE). Además se establecen otras limitaciones: «Ningún partido político podrá contar con más de 300 diputados por ambos principios [es decir, el mayoritario y el proporcional]. En ningún caso, un partido político podrá contar con un número de diputados por ambos principios que representen un porcentaje del total de la Cámara que exceda en ocho puntos a su porcentaje de votación nacional emitida. Esta base no se aplicará al partido político que, por sus triunfos en distritos uninominales, obtenga un porcentaje de curules [escaños] del total de la Cámara, superior a la suma del porcentaje de su votación nacional emitida más el ocho por ciento» (art. 15.3 de la LGIPE).

El principio de no reelección consecutiva de los legisladores sufrió varios intentos de reforma antes de su modificación mediante la reforma constitucional de 10 de febrero de 2014. Las iniciativas de reforma más importantes tuvieron lugar en 196443, 2005, 2007 y $2009^{44}$. Ninguna de ellas tuvo éxito. La razón es que, según el artículo 135 de la Constitución, las reformas constitucionales exigen el voto de las dos terceras partes de los parlamentarios presentes y que sean aprobadas por la mayoría de las legislaturas de los estados. Esa mayoría cualificada no se puede alcanzar sin la voluntad concorde del PRI, que se ha había opuesto a los intentos de reformar la limitación consecutiva de mandatos parlamentarios.

Finalmente, los sucesivos intentos de reforma han confluido en la reforma constitucional de 10 de febrero de 2014, en materia políticoelectoral ${ }^{45}$. Se trata de una reforma que toca muchos aspectos de la Constitución. En lo que aquí interesa, se suprime la prohibición de reelección legislativa consecutiva de los diputados y senadores, pero no se sustituye por una reelección indefinida de los mismos, sino por una limitación absoluta de mandatos de hasta un máximo de doce años en cada una de las cámaras [cuatro mandatos consecutivos de tres años en la Cámara de los Diputados y dos mandatos consecutivos de seis años en la Cámara de los Senadores (art. 59 de la Constitución) $]^{46}$.

${ }^{43}$ CAREAGA, Maité. «El fracaso de la reforma reeleccionista de 1964- 1965», en Fernando DWORAK (coord.). El Legislador a Examen, México: FCE y la Cámara de Diputados, 2003.

${ }^{44}$ Sobre estas propuestas de reforma véase: TOVAR MENDOZA, Jesús. «Condicionantes políticos...», op. cit. Págs. 191 y ss., CORTEZ SALINAS, Josafat. "La propuesta de la reelección inmediata...», op. cit. págs. 132 y ss.

${ }^{45}$ Decreto por el que se reforman, adicionan y derogan diversas disposiciones de la Constitución Política de los Estados Unidos Mexicanos, en materia política-electoral ( Diario Oficial (Primera Sección), lunes 10 de febrero de 2014).

${ }^{46}$ Artículo 59. «Los Senadores podrán ser electos hasta por dos periodos consecutivos y los Diputados al Congreso de la Unión hasta por cuatro periodos consecutivos. 
Se añade un requisito adicional: «La postulación sólo podrá ser realizada por el mismo partido o por cualquiera de los partidos integrantes de la coalición que los hubieren postulado, salvo que hayan renunciado o perdido su militancia antes de la mitad de su mandato». Es decir, se obliga a los parlamentarios, si quieren ser reelegidos, a permanecer en el mismo partido por el que obtuvieron el mandato inmediatamente anterior, salvo que cesen como militantes del partido antes de la mitad del mandato. Si el cese es posterior, se entiende que no podrán presentarse a la reelección.

La vinculación partitocrática del parlamentario para la reelección plantea problemas en el caso de candidatos independientes (que han presentado su candidatura al margen de los partidos). En este caso puede entenderse o bien que estos candidatos no pueden ser reelegidos para un segundo mandato, o bien que se les aplica la limitación de mandatos del artículo 59 pero no el requisito adicional de ser postulados por el mismo partido que previamente les hubiera elegido (requisito, obviamente, de imposible cumplimiento).

Se trata de una limitación de mandatos muy laxa (doce años para cada una de las cámaras), por lo que no parece que vaya a ser eficaz. Una misma persona (si cuenta con el apoyo de su partido) podrá ocupar el cargo de diputado durante doce años, y después otros doce años el de senador; a partir de aquí podrá postularse para cualquier otro cargo público electivo. Es decir, podrá dedicarse profesionalmente a la política de por vida, lo cual va contra el propósito mismo de la técnica constitucional de la limitación de mandatos.

Se han achacado al principio de no reelección consecutiva los principales males políticos de Méjico, como el sistema de partido hegemónico y el presidencialismo autoritario ${ }^{47}$. Sin embargo, cabe preguntarse por qué en los estados federados de los Estados Unidos que han establecido la limitación de mandatos parlamentarios (en su modalidad consecutiva o incluso absoluta) y con un sistema electoral similar (de mayoría relativa), no se ha producido el fenómeno de hegemonía de un partido y de presidencialismo autoritario. Creo que la respuesta hay que hallarla en la forma de organización de los partidos políticos y de selección de los candidatos dentro de los mismos.

\footnotetext{
La postulación sólo podrá ser realizada por el mismo partido o por cualquiera de los partidos integrantes de la coalición que los hubieren postulado, salvo que hayan renunciado o perdido su militancia antes de la mitad de su mandato».

${ }^{47}$ Véase, por ejemplo, LÓPEZ RUBÍ CALDERÓN, José Ramón. «El artículo 59 constitucional y el autoritarismo mexicano vigesímico. Una síntesis explicativa.», CONfines, núm. 2/4 agosto-diciembre 2006, págs. 73-78.
} 
La raíz del problema no está en el principio de no reelección consecutiva de los parlamentarios, sino en la organización oligárquica y centralizada de los partidos políticos en Méjico, algo que no se da en Estados Unidos, donde existen elecciones primarias (abiertas o cerradas) para la elección de los candidatos a los cargos públicos electivos. Este es el factor diferencial determinante.

Es esa falta de democracia interna de los partidos, y en especial, la confección de las listas por el comité ejecutivo del partido (o incluso por el propio Presidente de la República) y no por la libre decisión de las bases del partido, lo que, principalmente, parece haber llevado a la centralización del poder en el PRI y al presidencialismo autoritario.

En consecuencia, del contraejemplo mejicano podemos extraer la conclusión de que la limitación de mandatos debe ser combinada con una profunda mejora de la democracia interna de los partidos políticos, en especial en la forma de elección de los candidatos a cargos públicos electivos; de lo contrario se convertirá en un simple reparto de cargos entre unos pocos oligarcas dentro de los partidos.

\section{VENTAJAS O EFECTOS POSITIVOS DE LA LIMITACIÓN DE MANDATOS}

\section{III.1. Cuestiones preliminares}

Para indagar las ventajas e inconvenientes, los efectos positivos y negativos, de la limitación de mandatos sobre el sistema político, debemos tener en cuenta diversos factores diferenciales que harán que los efectos puedan variar de un país a otro, o dentro de un mismo país, de un ente territorial a otro. Así, por ejemplo, debemos tener presente la forma de gobierno (presidencial o parlamentaria) a la hora de determinar los efectos de la limitación de mandatos sobre las relaciones entre poder legislativo y poder ejecutivo.

También es preciso tomar en consideración el sistema electoral: en especial si es mayoritario de mayoría relativa en circunscripciones uninominales o muy pequeñas, como sucede en los estados federados de los Estados Unidos afectados por la limitación de mandatos, o para la elección de la mayoría de los diputados y senadores en Méjico; o si por el contrario es un sistema electoral proporcional, en circunscripciones plurinominales, como se establece para la designación de una minoría de diputados y senadores en Méjico y se articula en España para la elección de los miembros del Congreso, diputados auto- 
nómicos, miembros del Parlamento Europeo, concejales en municipios de más de 250 habitantes, etc. Por ejemplo, el sistema electoral puede influir sobre los efectos de la limitación de mandatos en las relaciones entre los electores y parlamentarios.

Otro elemento que debe ser tenido en cuenta es la organización de los partidos políticos: por ejemplo, si en los partidos hay poco disciplina de voto y se da una fuerte democracia interna, sobre todo en la designación de los precandidatos, con elecciones primarias (abiertas o cerradas), como es el caso de Estados Unidos ${ }^{48}$; o si por el contrario, se trata de partidos con una fuerte disciplina de voto y escasa democracia interna, como en Méjico y en España (con carácter general). Este factor es determinante, por ejemplo, para indagar los efectos de la limitación de mandatos sobre las relaciones entre poder legislativo y ejecutivo, o entre representantes y representados.

Finalmente, debe ponderarse la propia configuración de la limitación de mandatos. Por ejemplo, no producirá los mismos efectos sobre la carrera profesional y la renovación de las élites políticas ${ }^{49}$ una limitación de mandatos corta (seis u ocho años) o larga (12 o 24 años), absoluta o consecutiva, parcial o total, etc ${ }^{50}$.

Para analizar los posibles efectos de la limitación de mandatos sobre diversos elementos del sistema político, hemos partido de los estudios ya realizados en la literatura académica norteamericana, teniendo presente que sus resultados son preliminares, puesto que los límites de mandato entraron en vigor en algunos estados de los Estados Unidos desde mediados de los noventa, y todavía, unos veinte años después, sus efectos se siguen desplegando ${ }^{51}$.

Mientras el estudio de las ventajas e inconvenientes es apriorístico y meramente deductivo, el de los efectos positivos y negativos tiene

${ }^{48}$ Un análisis de los procedimientos de selección de los candidatos en los partidos puede verse en PÉREZ MONEO, MIGUEL; La selección de los candidatos electorales en los partidos, Centro de Estudios Políticos y Constitucionales, Madrid, 2012, especialmente Capítulo IV.

${ }^{49}$ Sobre el concepto de élites políticas, véase, entre otros: BARAS, Monserrat (2001). "Las élites políticas», en Manuel ALCÁNTARA y Antonia MARTÍNEZ (Eds.). Política y Gobierno en España, 2. ${ }^{\circ}$ Edición, Valencia, 2001, págs. 423-447.

${ }^{50}$ Ponen de manifiesto este aspecto: KURTZ, Karl T.; CAIN, Bruce E.; NIEMI, Richard G. (Eds.). Institutional Change in American Politics: The Case of Term limits, op. cit. pág. 186), CARESS, Stanley M. and KUNIOKA, Todd T. Term limits and Their Consequence..., op. cit. pág. 168.

${ }^{51}$ Advierten sobre el carácter preliminar y no definitivo de sus conclusiones: CAREY, John M.; Richard G. NIEMI and Linda W. POWELL; Term limits in the state legislature, University of Michigan, Michigan, 2000, pág. 128; CARESS, Stanley M. and KUNIOKA, Todd T. Term limits and Their Consequence..., op. cit., pág. 168. 
carácter inductivo y se basa en datos aportados por estudiosos de la materia y en la correspondiente interpretación de los mismos.

Sólo se han tenido en cuenta las ventajas o efectos positivos y los inconvenientes o efectos negativos que han sido considerados más relevantes, sin pretender agotar la materia.

\section{III.2. El mayor reparto del poder político}

Uno de los fines principales de la limitación de mandatos (especialmente de los mandatos parlamentarios) es atender a una mayor distribución o reparto del poder político entre los ciudadanos. Esta es una idea presente entre los que propugnan la limitación de mandatos parlamentarios en Estados Unidos: llevar a más personas a servir en los parlamentos, de forma que estos se transformen en "parlamentos ciudadanos $»^{52}$.

A su vez, la mayor distribución del poder político tiene su fundamento teórico en lo que DAHL denomina «la lógica de la igualdad ${ }^{53}$, y que los griegos llamaban «isonomía». Como ha dicho GARCÍA MORENO, «no hay duda de que la palabra que mejor caracterizaba al nuevo ordenamiento político ateniense [se refiere a la reforma de Clístenes entre el 508 y 500 a C.], hasta el punto de ser utilizada como eslogan por sus partidarios, era isonomía. Un término que significaba igual distribución, reparto de derechos y deberes por igual, igualdad de poderes entre los miembros del cuerpo cívico» ${ }^{54}$. En efecto, la isonomía no era sólo la igualdad ante la ley sino la igualdad de participación política, lo que implicaba la misma oportunidad para gobernar para todos los ciudadanos ${ }^{55}$, es decir, turnarse en el ejercicio del poder.

Dirá Aristóteles, en su obra Política, que:

«Fundamento básico del sistema democrático es la libertad (...), y un rasgo de la libertad es el ser gobernado y gobernar alternativamente. (...) Un rasgo también es el vivir como se quiera: pues afirman que esto es obra de la libertad, si es que es propio del esclavo el no vivir como

${ }^{52}$ Idea recogida en KURTZ, Karl T.; CAIN, Bruce E.; NIEMI, Richard G. (Eds.). Institutional Change in American Politics: The Case of Term limits, op. cit. pág. 16.

${ }^{53}$ DAHL, R. La democracia. Una guía para los ciudadanos, trad. F. Vallespín, Taurus, Madrid, 1999, pág. 16.

${ }^{54}$ GARCÍA MORENO, Luis A. «El establecimiento de la democracia ateniense: igualdad y libertad», en GARCÍA MORENO, Luis A. y TORTELLA, Gabriel (eds.). La democracia ayer y hoy, Gadir Editorial, Madrid, 2008, pág. 75.

55 SINCLAIR, R. K. Democracia y participación en Atenas, Alianza Editorial, 1999, pág. 41. 
quiera. Así que esto es un segundo elemento definidor de la democracia, y de ahí ha venido el no dejarse gobernar en principio por nadie, y si no, por turno; y ahí se contribuye a la libertad basada en la igualdad».56

De la isonomía, de la igualdad entre todos los ciudadanos, derivan algunos rasgos característicos de la democracia ateniense: el que la mayoría de los cargos sean elegidos por sorteo (el sorteo al no hacer distinciones entre los ciudadanos según sus méritos o capacidad, es la forma de elección más igualitaria e indiscriminada); el que la duración de los cargos sea muy breve (un año como término medio), para evitar que nadie sea mandado por otros mucho tiempo y que de esto pueda derivarse alguna ventaja; y el hecho de que nadie pueda desempeñar dos veces una misma magistratura, con la finalidad de dar a otros oportunidades de gobernar a su vez.

Todos estos rasgos, además de otros, son mencionados por Aristóteles:

«Siendo estos los supuestos y tal el origen de la democracia, he aquí las medidas democráticas: que se elijan todos los cargos entre todos; que todos manden sobre cada uno y cada uno alternativamente sobre todos; que se sorteen los cargos, todos o lo que no requieren experiencia y técnica; que las magistraturas no dependan en absoluto de la renta o de una renta mínima; que el mismo no desempeñe dos veces ninguna magistratura o en raras ocasiones, o unas pocas con excepción de las de la guerra; que sean de poca duración lo cargos, todos o los que sea posible (...)». ${ }^{57}$

Es evidente que la limitación de mandatos contribuye a un mayor reparto del poder político. Supongamos que se establece una limitación de mandatos absoluta (de por vida) de cuatro años para ser parlamentario. Si hasta entonces una persona ha sido parlamentario durante 24 años, a partir de la entrada en vigor de la limitación del mandatos, el mismo cargo y durante el mismo tiempo (24 años) se repartirá entre seis personas (cada una de ellas ocupando el cargo por un máximo de cuatro años).

El efecto del reparto del poder político entre los ciudadanos se da, con mayor o menor intensidad, en todos los supuestos de limitación de mandatos. Sin embargo, puede ocurrir que el reparto del poder político no llegue a todos los ciudadanos, sino que se quede dentro de una oligarquía cerrada. Por ejemplo, si la limitación de mandatos es de baja intensidad (una modalidad consecutiva, o absoluta pero con

${ }^{56}$ Cita tomada de DEL AGUILA, Rafael, FERNANDO VALLESPÍN y otros; La democracia en sus textos, Alianza Editorial, 2007, pág. 47. Las cursivas no son del original. Sobre la rotación de los cargos en el Consejo de los Quinientos, SINCLAIR, R. K.; Democracia y participación en Atenas, op. cit. pág. 124.

${ }^{57}$ Ibidem. 
una limitación en un período muy laxo de tiempo) y se combina con una organización oligárquica de los partidos políticos, esto determinará que el reparto de los cargos públicos electivos se produzca tan solo entre unas mismas personas que se turnan en el ejercicio del poder, saltando de un cargo político a otro. Si este efecto se produjera, la limitación de mandatos no habría cumplido su finalidad esencial: el reparto del poder político entre los ciudadanos y la renovación de las élites políticas.

\section{III.3. Algunas propuestas al respecto}

El mayor o menor reparto del poder político depende no sólo de la modalidad de limitación de mandatos (absoluta o consecutiva) sino también de su extensión y alcance. En efecto, el reparto del poder político sería mayor si se aplicara a todos los cargos públicos electivos y no sólo a los parlamentarios, y a todos los niveles territoriales de gobierno. Incluso el reparto sería mayor si la limitación de mandatos se aplicara también a los cargos directivos de los partidos políticos, e incluso de los sindicatos y asociaciones empresariales (A todas estas asociaciones les exige la Constitución española que su estructura interna y funcionamiento sean democráticos, arts. 6 y 7). Para un mayor efecto, podría ampliarse el número de cargo públicos electivos (pasando a ser de elección popular cargos que hasta la fecha han sido designados por el ejecutivo o el legislativo), y aplicar la limitación de mandatos también a estos nuevos cargos electivos.

Todavía para conseguir un mayor reparto del poder político, se podría establecer un régimen muy estricto de incompatibilidades, aplicando el principio de "una persona, un cargo». De modo que se prohíba la acumulación de varios cargos en una misma persona, salvo supuestos muy excepcionales.

En especial, debería ser incompatible ocupar al mismo tiempo un cargo público electivo y un cargo directivo en un partido político. En este sentido, FERRAJOLI propone «la incompatibilidad entre cargos de partido y cargos públicos electivos, con el objeto de impedir el interés personal de los titulares de los primeros de auto-elegirse como titulares de los segundos» ${ }^{58}$. De modo que, «sólo esta exclusión y esta alteridad, merced a la cual el que se presenta como candidato a las funciones representativas debería dejar los cargos de partido y vice-

${ }^{58}$ FERRAJOLI, Luigi. Poderes salvajes. La crisis de la democracia constitucional, Editorial Mínima Trotta, Madrid, 2011, pág. 92. 
versa, serviría para producir una recíproca autonomía, beneficiosa y saludable para ambos» ${ }^{59}$.

\section{III.4. La renovación permanente de las élites políticas}

La medida aquí estudiada se justifica no sólo en la necesidad de un mayor reparto del poder político, sino también en la necesidad de una renovación permanente y obligada de las élites políticas.

¿Pero por qué es necesario renovar a los miembros de la clase política? La profesionalización de la política crea una clase política distante de las demandas ciudadanas, o con intereses contrapuestos a los de la mayoría de la población, lo cual es contradictorio con el sistema democrático. Además, el mantenerse largo tiempo en el ejercicio del poder puede dar lugar a la creación de redes clientelares y corrupción política en último término ${ }^{60}$.

Otro motivo para renovar la clase política es el desprestigio en que han caído en España los políticos profesionales. En efecto, en las encuestas del Centro de Investigaciones Sociológicas sobre la valoración de los políticos, ninguno de ellos llega al cinco (sobre diez puntos) ni en el gobierno ni en la oposición ${ }^{61}$. Una forma de salir de esta situación de impasse puede ser mediante la renovación de la clase política en ideas y personas ${ }^{62}$. La renovación no debería producirse una sola vez sino que, para evitar que el sistema vuelva a anquilosarse, debería ser continua, es decir, establecida como regla de juego en la Constitución. De ahí la necesidad de prohibir la reelección de una misma persona, y no sólo respecto de los miembros del poder ejecutivo, sino respecto de todos los cargos públicos representativos (diputados, senadores, diputados autonómicos, concejales, etc.).

En definitiva, en un régimen de democracia representativa como el nuestro, se puede comprender que sean unos pocos los que manden, u ocupen cargos públicos representativos, ¿pero por qué habrían

${ }^{59}$ FERRAJOLI, Luigi. Poderes salvajes..., op. cit. pág. 93.

${ }^{60}$ Sobre esto, véase el epígrafe III.6 de este trabajo.

${ }^{61}$ Véase, por ejemplo, el barómetro del CIS correspondiente al mes de julio de 2014. Puede consultarse en http://www.cis.es/cis/export/sites/default/-Archivos/Marginales/3020_3039/3033/es3033mar.pdf (Página visitada el 25 de agosto de 2014).

${ }^{62}$ En este sentido, ESTELLA, Antonio. «Por la limitación de mandatos en la política», Elpaís, 15 de junio de 2013. http://elpais.com/elpais/2013/06/05/opinion/1370438662_591109.html. 
de ser siempre los mismos? Los políticos profesionales ${ }^{63}$, con su vocación de hacer de la política una profesión de por vida, actúan como tapón para la renovación de las élites y de las ideas políticas, renovación que, sobre todo en situaciones de crisis, puede llegar a ser fundamental.

La idea de que gobiernen los expertos, los «profesionales», llevada a sus últimas consecuencias, conduciría a una república de «sabios», al modo de la república de Platón, pero no a la democracia. En cambio, la democracia exige que la política, que concierne a todos los ciudadanos $^{64}$, pueda ser llevada a cabo por aficionados, a los cuales pueden rendir su consejo, cuando les sea requerido, los «expertos», es decir, los que tienen conocimientos técnicos en determinados asuntos.

Siguiendo estas reglas, el político se habrá convertido en un ciudadano más (y no en un sujeto privilegiado o un profesional de la política) que de manera ocasional (por un máximo de un mandato o dos) presta voluntariamente (aunque de manera debidamente retribuida) sus servicios a la comunidad política, y luego vuelve a su actividad profesional, laboral o empresarial (previa reserva del puesto de trabajo) sin obtener por ello privilegio económico alguno (lo que implica la supresión de las pensiones vitalicias por dedicación a la política).

En efecto, una de las finalidades básicas perseguidas por quienes propugnaron las limitaciones de mandato era asegurar que los parlamentos permanezcan como "cuerpos ciudadanos», no como organizaciones dominadas por políticos de carrera ${ }^{65}$.

Con anterioridad a la implantación de los term limits en algunos estados de los Estados Unidos, el sistema político estaba marcado por una tremenda ratio de reelección de titulares, es decir, de personas que competían por un cargo electivo habiendo sido titulares del cargo en el anterior mandato. En 1988, los titulares que se presentaban a la reelección volvían al Congreso Federal en un 96 por ciento de los casos. En 1990, en el 98 por ciento ${ }^{66 .}$ La razón es que los parlamentarios

${ }^{63}$ Sobre el concepto de político profesional véase WEBER, Max. El político y el científico, Alianza Editorial, Madrid, 2005.

${ }^{64}$ Idea bellamente expresada en el mito de Protágoras, recogido en la obra homónima de Platón. Véase: PLATÓN; Protágoras, Editorial Gredos, Madrid., 2010.

${ }^{65}$ Idea recogida en KURTZ, Karl T.; CAIN, Bruce E.; NIEMI, Richard G. (Eds.). Institutional Change in American Politics..., op. cit. pág. 16. En el mismo sentido, CARESS, Stanley M. and KUNIOKA, Todd T. Term limits and Their Consequence..., op. cit., pág. 171 .

${ }^{66}$ JACOB, Paul. «From de Voters with Care», en CRANE, Edward H. and PILON, Roger (Eds.) (1994), The politics and Laws of term limits, Washington: The Cato Institute, 1994, págs. 27 y ss, esp. pág. 30. Asimismo, Andrea SÁNCHEZ considera que 
titulares gozan de ventajas y privilegios de los que carecen quienes se presentan por primera vez a una elección: están exentos de pagar tasas por enviar correo a los electores (the franking privilege), cuentan con un equipo de asesores (Congressional Staff), se han construido a sí mismos un estudio de radio y televisión exento de pagar impuestos (Media advantages) ${ }^{67}$.

Así pues, los proponentes de la limitación de mandatos sostenían que purgar los parlamentos de «titulares atrincherados» podría atraer una nueva generación (new breed) de legisladores ciudadanos que podrían volver a sus comunidades después de un breve período de servicio público, para vivir las leyes que ellos mismos habían aprobado ${ }^{68}$.

Habría que preguntarse si, en realidad, se han alcanzado los objetivos de los proponentes de la limitación de mandatos respecto de la renovación de las élites políticas. La mayoría de los autores coinciden en que el objetivo más básico, de renovación de las personas, se ha alcanzado. La limitación de mandatos ha brindado nuevas caras a los parlamentos estatales. Así, se constata que se ha incrementado el número de asientos abiertos (open seats), es decir, puestos por los que compiten personas que en el anterior mandato no habían sido titulares de ese cargo electivo, para las elecciones a la cámara de representantes (diputados) de Michigan y de California ${ }^{69}$.

Las limitaciones de mandato han reducido el extraordinario poder de los titulares durante las elecciones. Y como resultado, han sido elegidos a los parlamentos estatales grupos de ciudadanos más diver$\operatorname{sos}^{70}$. Generalmente, cuanto más profesionalizados han sido los parlamentos (como el de California) mayor impacto han tenido los term

el establecimiento de la reelección legislativa indefinida en Méjico puede producir, como desventaja, un «enquistamiento nocivo de las élites en el poder», y, en todo caso, impide la renovación de las élites en el poder o la pone en «manos de muy pocos»- ANDREA SÁNCHEZ, Francisco José de. "Reelección legislativa consecutiva: una iniciativa de reforma riesgosa», Boletín Mexicano de Derecho Comparado, México, núm.103, enero-abril de 2002, págs. 295-305, esp. pág. 302.

${ }^{67}$ JACOB, Paul; «From de Voters with Care», op. cit. pág. 30. Hay que tener en cuenta, además, que el intento de establecer límites de mandato para los miembros del Congreso fue declarado inconstitucional por el Tribunal Supremo Federal, como hemos visto más arriba.

${ }^{68}$ SARBAUGH-THOMPSON, Marjorie; LYKE THOMPSON, Charles D. ELDER, John Strate, and Richard C. ELLING. Political and Institutional Effects of Term limits, Gordonsville, VA, USA: Palgrave Macmillan, 2004, pág. 3.

${ }^{69}$ SARBAUGH-THOMPSON, Marjorie; LYKE THOMPSON, Charles D. ELDER, John Strate, and Richard C. ELLING. Political and Institutional Effects of Term limits..., op. cit. Pág. 192.

${ }^{70}$ KURTZ, Karl T.; CAIN, Bruce E.; NIEMI, Richard G. (Eds.). Institutional Change in American Politics..., op. cit. pág. 16. 
limits, pues en esos parlamentos las rotaciones eran menos frecuentes antes de la implantación de esta medida ${ }^{71}$.

Sin embargo, no se ha alcanzado el propósito más ambicioso de los proponentes de las limitaciones de mandato: acabar con los políticos de carrera y sustituirlos por políticos ciudadanos.

Como ha dicho CAIN, «encontramos que las limitaciones de mandato han alterado el modelo de carrera política más que acabar con él. El típico camino profesional fluye desde la Asamblea al Senado y después hacia los altos cargos públicos o hacia el gobierno local» ${ }^{72}$. Es decir, los parlamentarios continúan con su carrera política, una vez llegado al límite de mandato, saltando de un cargo público electivo a otro ${ }^{73}$.

\section{III.5. Algunas propuestas al respecto}

Entonces, ¿debemos concluir que los term limits han fracasado en su propósito? Las limitaciones de mandato, tal como se han configurado en Estados Unidos y en Méjico, sí han permitido una renovación de caras y de personas, pero han sido insuficientes para lograr el propósito más ambicioso de acabar con los políticos de carrera y sustituirlos por políticos ciudadanos. Esto último propósito sólo puede alcanzarse estableciendo unas limitaciones de mandato mucho más estrictas.

En efecto, si el límite de mandatos es parcial (para un determinado cargo público) y consecutivo, los parlamentarios afectados, esperarán pacientemente en otro cargo público electivo, si es posible, para volver al parlamento transcurrido el tiempo establecido. Si el límite de mandato es para cada una de las Cámaras (sea absoluto o consecutivo), los afectados que quieran mantenerse en la política se presenta-

${ }^{71}$ KURTZ, Karl T.; CAIN, Bruce E.; NIEMI, Richard G. (Eds.). Institutional Change in American Politics..., op. cit. pág. 186.

${ }^{72}$ CAIN, Bruce E.; Adapting to term limits: recent experiences and new directions, Public Policy, Institute of California, San Francisco, CA., 2004, pág. 97. Asimismo, KURTZ, Karl T.; CAIN, Bruce E.; NIEMI, Richard G. (Eds.). Institutional Change in American Politics..., op. cit. pág. 97.

${ }^{73}$ Este efecto, de salto de un cargo político electivo a otro, es puesto de manifiesto, asimismo, por otros autores: CARESS, Stanley M. and KUNIOKA, Todd T.; Term limits and Their Consequence..., op. cit., págs. 171 y 172; CAREY, John M.; Richard G. NIEMI and Linda W. POWELL. Term limits in the state legislature, University of Michigan, Michigan, 2000, págs. 126 y 127; SARBAUGH-THOMPSON, Marjorie; LYKE THOMPSON, Charles D., ELDER, John Strate, and Richard C. ELLING. Political and Institutional Effects of Term limits, op. cit. pág. 188. 
rán como candidatos a la otra cámara legislativa. Si el límite es para ambas cámaras (sea absoluto o consecutivo), los sujetos afectados, si quieren continuar profesionalmente en política, se presentarán como candidato a otro cargo público electivo.

La única manera de acabar con estos saltos de un cargo público electivo a otro es establecer una limitación de mandatos consecutiva pero total, es decir, para todo cargo público electivo: mediante la cual, el afectado, una vez que llevara un tiempo (uno o dos mandatos) ocupando uno o más cargos electivos, fueran cuales fueran éstos, debería dejar la política y volver a su actividad privada por un tiempo estipulado (uno o dos mandatos) antes de volver a postularse para cualquier cargo público electivo. De esta forma la carrera política del sujeto afectado, sería, en el mejor de los casos, intermitente en el tiempo. Todavía se podría afinar un poco más y extender esta limitación de mandatos, total y consecutiva, no sólo a los cargos públicos electivos, sino también a los cargos públicos de confianza, a fin de evitar que el sujeto afectado permaneciera a la sombra en un cargo de confianza antes de saltar nuevamente a la arena política.

En cambio, sería excesiva una limitación de mandatos total y absoluta: pues sólo concedería a cada persona una única oportunidad en su vida para ejercer un cargo público electivo, fuera el que fuese éste.

También se podría adoptar una posición intermedia, que obligara a una carrera política ascendente: estableciéndose una limitación de mandatos total pero restringida a todos los cargos públicos electivos de un mismo ente territorial: el sujeto afectado podría aspirar a otros cargos de otros entes territoriales, siempre que la carrera política fuera ascendente, es decir, de un ente territorial a otro de mayor extensión territorial (del municipio a la Comunidad Autónoma, de ésta al Estado, y de éste a las instituciones de la Unión Europea).

\section{III.6. La prevención contra la aparición de redes clientelares y de prácticas corruptas}

Si todo el que ejerce el poder tiende a abusar de él ${ }^{74}$, cuanto más tiempo permanezca en el poder, más probabilidades tendrá de abusar

${ }^{74}$ «Pero es una experiencia eterna, que todo hombre que tiene poder siente la inclinación de abusar de él, yendo hasta donde encuentra límites. ¡Quién lo diría! La misma virtud necesita límites»- MONTESQUIEU. Del espíritu de las leyes, Tecnos, Madrid, 1998, (Traducción de Mercedes Blázquez y Pedro de Vega). (Original en francés de 1748), pág. 106. 
del mismo. Es cierto que la corrupción podría darse también entre políticos que ejercieran el cargo por poco tiempo, pero es mucho más probable cuanto más tiempo permanezcan en el ejercicio del poder. Y en todo caso, una limitación de mandatos efectiva no daría tiempo a que se formaran redes clientelares ${ }^{75}$.

En este sentido, se ha dicho que el restablecimiento de la reelección indefinida de los legisladores en Méjico podría hacer que aumentasen las redes clientelares y la corrupción ${ }^{76}$.

Hay que tener en cuenta que la posible corrupción de los parlamentarios, o de otros cargos electos, puede ir ligada a la corrupción de los partidos políticos, en los que a veces ocupan cargos directivos ${ }^{77}$.

Una forma de dificultar este tipo de prácticas corruptas puede consistir, como se propugna en este trabajo, en establecer la incompatibilidad entre ocupar un cargo directivo en un partido y, al mismo tiempo, un cargo público electivo o de confianza, además de implantar la limitación de mandatos de todos estos cargos.

\section{POSIBLES INCONVENIENTES O EFECTOS NEGATIVOS Y CÓMO PALIARLOS}

\section{IV.1. Una cuestión preliminar: la refutación de algunas objeciones teóricas y prácticas}

Antes de examinar los posibles inconvenientes de la limitación de mandatos, y de intentar remediarlos, es preciso refutar algunas objeciones teóricas y prácticas que se han presentado en relación con esta técnica constitucional

a) Primera objeción: el turnarse en el poder no es un requisito de la democracia

«Pese a la importancia que tiene la alternabilidad en el gobierno para la teoría democrática, ella por sí sola no es un principio mismo de la democracia, comparable con el principio de la elección de los mandatarios y de la periodicidad de las elecciones. Lo es sólo en cir-

${ }^{75}$ En este sentido, RUIZ-RICO RUIZ, Gerardo. «La lucha contra la corrupción desde el Estado constitucional de Derecho: la legislación sobre financiación de partidos políticos en España», Cuadernos Manuel Giménez Abad, núm.7, junio 2014, págs. 223-248, esp. pág. 229.

${ }^{76}$ ANDREA SÁNCHEZ, Francisco José de. «Reelección legislativa consecutiva...», op. cit., págs. 302 y 304.

${ }^{77}$ En este sentido, RUIZ-RICO RUIZ, Gerardo. «La lucha contra la corrupción...», op. cit., pág. 240. 
cunstancias concretas que en América Latina legitimaron esta previsión constitucional, tesis que se confirma por las excepciones a la normativa siempre presentes en esta región»».

En contra de esta opinión, se puede argumentar que el hecho de que no haya sido un requisito de la democracia constitucional históricamente, desde las primeras revoluciones liberales, no significa que no sea un requisito teórico, derivado del principio de igualdad política, lo que exige el reparto y distribución del poder político y la participación efectiva de los ciudadanos en su ejercicio: la única forma de participar de manera efectiva en el poder es ejerciéndolo, lo cual exige su distribución, permitir que los ciudadanos se turnen en la gestión de los cargos públicos electivos, y para ello es preciso establecer la limitación de mandatos. Así fue entendido en la democracia ateniense. Así fue entendido, aunque referido tan sólo a una reelección no consecutiva, en los primeros textos constitucionales de Francia (1791) y de España (1812). Que hasta ahora no se haya visto como un requisito de la democracia moderna sólo da muestras de la miopía (tal vez deliberada) de la teoría democrática liberal (especialmente del modelo elitista competitivo $^{79}$ ) respecto de los principios mismos de la democracia.

b) Segunda objeción: un país no es más democrático porque recoja el principio de no reelección de los cargos públicos electivos

«Por otra parte, no existe ningún parámetro teórico, es decir, no relacionado con la contingencia, para determinar comparativamente el valor democrático de la reelección inmediata y por una sola vez, así como de la no reelección del ejecutivo. El modelo estadounidense (periodo electoral de cuatro años, posibilidad de reelección inmediata por una sola vez) es tan democrático como la no reelección». ${ }^{80}$

Aunque el argumento se refiere al poder ejecutivo, también sería aplicable al legislativo. Se puede contra-argumentar que, por supuesto, un país no es más democrático porque adopte este principio de forma aislada. Una democracia es un conjunto complejo de principios, reglas y prácticas políticas. Pero sí se puede afirmar que, a igualdad de otros principios y reglas, sería teóricamente más democrático un país donde se prohibiera o limitara la reelección de sus cargos

${ }^{78}$ NOHLEN, Dieter. «XV. La reelección», en Dieter NOHLEN, Daniel ZOVATTO, Jesús OROZCO, José THOMPSON. (Comps.). Tratado de derecho electoral comparado de América Latina, 2a ed., México: FCE, Instituto Interamericano de Derechos Humanos, Universidad de Heidelberg, International IDEA, Tribunal Electoral del Poder Judicial de la Federación, Instituto Federal Electoral, 2007, págs. 287-293, esp. pág. 290.

${ }^{79}$ Para un estudio de diferentes modelos de democracia a lo largo de la Historia, véase: HELD, David; Modelos de democracia, Alianza Editorial, Madrid, 2007.

${ }^{80}$ NOHLEN, Dieter. «XV. La reelección», op. cit., pág. 290. 
públicos electivos, porque, entre otras razones, permitiría un mayor reparto del poder político.

c) Tercera objeción: la limitación de mandatos no es propia del régimen parlamentario

Dice Nohlen que «la medida no se da en los regímenes democráticos de tipo parlamentario» ${ }^{81}$.

Como se puede comprobar, en este caso no se trata de un argumento de tipo teórico, sino más bien factual, histórico. El argumento nada añade al debate teórico, pues la situación puede cambiar.

En efecto, parece ser que los autores que sostienen esta afirmación están pensando en la limitación de mandatos aplicada al poder ejecutivo, que, como es sabido, en el régimen parlamentario es elegido por el parlamento, no directamente por el pueblo, y en teoría puede ser revocado igualmente por el parlamento, por lo que, en principio, no es necesario limitar su mandato frente al temor de una deriva autoritaria del poder gubernamental.

Sin embargo, ningún obstáculo teórico o técnico impide que, en el régimen parlamentario, se aplique la limitación de mandatos a los miembros del parlamento, como sucede en los regímenes presidenciales que hemos visto.

Es más, la limitación de mandatos podría aplicarse en el régimen parlamentario a los miembros del gobierno de una manera muy sencilla: vinculando la condición de miembro del gobierno a la condición de parlamentario, como sucede en el régimen parlamentario clásico del Reino Unido, donde los miembros del gobierno deben ser designados obligatoriamente de entre los miembros del Parlamento ${ }^{82}$. Y como sucede en España a nivel local, donde el alcalde debe ser elegido entre los concejales (art. 196 LOREG), y a nivel regional, donde el Presidente de la Comunidad Autónoma debe ser elegido por la Asamblea de entre sus miembros (art. 152.1 CE). De este modo una persona afectada por una limitación de mandato parlamentario, una vez transcurrido el tiempo estipulado, no podría volver a presentarse como candidato a cualquiera de las cámaras del parlamento y, en consecuencia, no podría ser tampoco designado como miembro del Gobierno.

${ }^{81}$ NOHLEN, Dieter. "XV. La reelección», op. cit., pág. 290. En el mismo sentido, URQUIZU, Ignacio (2014). "Aclarémonos: ¿qué democracia queremos?», ElPaís, 12 de marzo de 2014.

${ }^{82}$ Véase FERNÁNDEZ SEGADO. «Capítulo I. El régimen político británico», en Juan FERRANDO BADÍA (Coord.). Regímenes politicos actuales, Tecnos, Madrid, 3. ${ }^{a}$ edición, 1995, págs. 69-190, esp. pág. 111. 


\section{IV.2. La inexperiencia de los parlamentarios y sus consecuencias negativas}

Los detractores de las limitaciones de mandato en Estados Unidos consideran que éstas disminuyen la experiencia necesaria para la formación de los políticos ${ }^{83}$, y constituyen una rémora para el gobierno eficaz $^{84}$.

En la práctica, durante la vigencia de la reelección no consecutiva de los parlamentarios, se ha destacado la escasa experiencia del legislador mexicano, puesto que en el periodo de 1934 a 1997, en promedio, solamente el catorce por ciento de los diputados federales contaban con experiencia previa como parlamentarios federales ${ }^{85}$.

Asimismo, para el caso de los parlamentarios de los estados federados mejicanos, PÉREZ VEGA señala que «un aplastante $85 \%$ de los diputados locales no tiene experiencia legislativa, ya sea local o federal ${ }^{86}$.

En Estados Unidos, CLUCAS ${ }^{87}$ ha confirmado que en California ha habido un declive en la experiencia de los legisladores. Pero la experiencia legislativa de los senadores es más amplia que la de los diputados, porque muchos de ellos han servido previamente en la Cámara baja.

La inexperiencia de los parlamentarios puede producir, entre otras, las siguientes consecuencias negativas:

a) Un parlamento débil en sus relaciones con el poder ejecutivo, lo que implica una menor fiscalización política del gobierno.

En Méjico, autores como TOVAR MENDOZA opinan que se puede reforzar el poder legislativo suprimiendo la prohibición de reelección

${ }^{83}$ EASTLAND, Terry. "The limits of term limits», en Commentary 95, vol.2, 1993, págs.53-55, KESLER, Charles R. «Bad Housekeeping: The Case against Congressional Term Limitation», en Policy Review, Summer, 1990, págs. 20-25, esp. pág. 24.

${ }^{84}$ CAIN, Bruce E. Adapting to term limits..., op. cit., págs. 46-47. Para el caso de Méjico, emplean argumentos similares NOHLEN, DIETER; "XV. La reelección», op. cit., pág. 292 y TOVAR MENDOZA, Jesús. "Condicionantes políticos...», op. cit. pág. 195.

${ }^{85}$ CAMPOS, E.; «Un congreso sin congresistas. La no-reelección consecutiva en el Poder Legislativo mexicano, 1934-1997», en Fernando DWORAK (Coord.), El legislador a examen. El debate sobre la reelección legislativa en México, México: Fondo de Cultura Económica/ Cámara de Diputados, 2003, págs. 98-151, esp. pág. 113.

${ }^{86}$ PÉREZ VEGA, Moisés. «La debilidad institucional de los congresos locales. Límites de la democratización mexicana y de la transformación de las relaciones Ejecutivo-Legislativo», Andamios. Revista de Investigación Social, Vol. 5, Núm. 10, abrilsin mes, 2009, págs. 253-278, esp. pág. 269.

${ }^{87}$ CLUCAS, Richard A. "California: The New Amateur Politics», en Rick FARMER, John David RAUSCH JR., and John C. GREEN. The test of time. Coping whith legislative term limits, Lexington Books, 2003, pág. 21. 
y permitiendo la reelección inmediata de los legisladores, dotando, de este modo, de mayor autonomía al parlamento tanto respecto del poder ejecutivo como respecto de los partidos ${ }^{88}$.

En Estados Unidos, los opositores a las limitaciones de mandato argumentan que «eliminando la experiencia y el conocimiento de los legisladores, los term limits debilitan la rama legislativa del gobierno. Un parlamento débil trastorna el equilibrio de poderes que es la base de la forma democrática de gobierno ${ }^{89}$.

En la práctica de la limitación de mandatos, KURTZ, CAIN y NIEMI constatan que en California ha declinado la influencia parlamentaria sobre el presupuesto. Sin embargo los efectos son menos obvios en otros estados, como Arkansas. Aunque la capacidad para funcionar ha sido debilitada, los parlamentos tienen todavía considerables poderes formales e informales sobre legislación, presupuestos y nombramientos. En resumen, se concluye que los term limits han debilitado a los parlamentos institucionalmente, especialmente en estados con límites absolutos (de por vida) que habían profesionalizado los parlamentos con baja rotación ${ }^{90}$.

Por su parte, CAIN considera que los nuevos legisladores encuentran significativos obstáculos en sus esfuerzos por controlar la rama ejecutiva. Carecen de la experiencia de sus predecesores y no disponen de las herramientas para descubrir y atacar fácilmente los errores burocráticos. En definitiva, para este autor, el gobierno ha ganado poder sobre el parlamento en las negociaciones de presupuesto y ha declinado el control del parlamento sobre las agencias del ejecutivo ${ }^{91}$.

CARESS y KUNIOKA opinan que se ha operado una transferencia del peso del poder del parlamento al ejecutivo, pero esto no se ha verificado en todos los supuestos de term limits $^{92}$.

${ }^{88}$ TOVAR MENDOZA, Jesús. «Condicionantes políticos...», op. cit. Pág. 196, donde cita en este sentido a LUJAMBIO, Alonso. «La Reelección de los Legisladores: Las Ventajas y los Dilemas», en Quórum, año V, núm. 38, México: Instituto de Investigaciones Legislativas de la Cámara de Diputados, 1996, pág. 23. JAIMES DELGADO insiste en esta idea de reforzamiento del poder legislativo mediante la reelección legislativa inmediata de los parlamentarios JAIMES DELGADO, David Alberto. "¿Cómo fortalecer ...?», op. cit., in totum.

${ }^{89}$ Argumento recogido en KURTZ, Karl T.; CAIN, Bruce E.; NIEMI, Richard G. (Eds.). Institutional Change in American Politics..., op. cit. pág. 17.

${ }^{90}$ KURTZ, Karl T.; CAIN, Bruce E.; NIEMI, Richard G. (Eds.). Institutional Change in American Politics..., op. cit. págs. 190 y 193.

${ }^{91}$ CAIN, Bruce E.; Adapting to term limits..., op. cit., págs. 87 y 99.

${ }^{92}$ CARESS, Stanley M. and KUNIOKA, Todd T. Term limits and Their Consequence..., op. cit., pág. 174. 
b) Se debilita el liderazgo de los presidentes de las cámaras legislativas y de los líderes parlamentarios.

Se considera que las limitaciones de mandato parlamentario han producido un liderazgo débil en los speakers y en los líderes parlamentarios, puesto que no hay tiempo para adquirir la experiencia suficiente para el liderazgo parlamentario ${ }^{93}$.

c) Pierde peso la Cámara de Diputados en relación con el Senado.

Las limitaciones de mandato suponen que el peso del poder político pasa de la Cámara de los diputados al Senado, donde suele haber políticos con experiencia previa en la Cámara baja ${ }^{94}$.

d) Aumenta el poder de los grupos de intereses y de los expertos sobre los parlamentarios aficionados.

Quienes se oponen a las limitaciones de mandato parlamentario opinan que, bajo este sistema, se incrementa el poder de los lobbies, personal legislativo y burócratas porque ellos poseen un conocimiento institucional sobre los asuntos públicos que han adquirido en el pasado ${ }^{95}$.

$\mathrm{Al}$ respecto, en la obra KURTZ, CAIN y NIEMI se muestra que los lobbies y grupos de intereses han tenido que trabajar duro para establecer relaciones con parlamentarios sujetos a term limits, pero la evidencia sugiere que su poder ha continuado imbatido, siempre aumentando y no decreciendo ${ }^{96}$.

Para otros, se ha incrementado la vinculación de los legisladores a los grupos de intereses para obtener información ${ }^{97}$.

e) Se dificulta la negociación y el acuerdo.

Se argumenta que la inexperiencia de los parlamentarios producida por las limitaciones de mandato dificulta la negociación y el acuerdo entre los parlamentarios de distintas formaciones políticas ${ }^{98}$.

${ }^{93}$ CARESS, Stanley M. and KUNIOKA, Todd T. Term limits and Their Consequence..., op. cit., pág. 173. En el mismo sentido, CAIN, Bruce E.; Adapting to term limits..., op. cit., pág. 98.

${ }^{94}$ CARESS, Stanley M. and KUNIOKA, Todd T. Term limits and Their Consequence..., op. cit., pág. 174.

${ }^{95}$ Argumento recogido en KURTZ, Karl T.; CAIN, Bruce E.; NIEMI, Richard G. (Eds.) Institutional Change in American Politics..., op. cit. pág. 192.

${ }^{96}$ Ibídem.

${ }^{97}$ SARBAUGH-THOMPSON, Marjorie; LYKE THOMPSON, Charles D. ELDER, JOHN STRATE, and Richard C. ELLING. Political and Institutional Effects of Term limits, op. cit., pág. 193.

${ }_{98}$ TOVAR MENDOZA, Jesús. «Condicionantes políticos...», op. cit. pág. 196. En el mismo sentido, ANDREA SÁNCHEZ, Francisco José de; «Reelección legislativa consecutiva...», op. cit., pág. 299. 
En Estados Unidos, CARESS y KUNIOKA consideran que los term limits aumentan el conflicto entre los miembros del parlamento, que pueden competir entre ellos por una vacante en diferentes cuerpos legislativos, y que puede producirse una atmósfera menos favorable a los pactos y coaliciones entre los parlamentarios ${ }^{99}$.

Asimismo, otros autores hallan signos de que los term limits desincentivan la cooperación entre los legisladores ${ }^{100}$.

\section{f) Disminuye la productividad legislativa.}

En Méjico, algunos argumentaban que la supresión de la cláusula constitucional que prohibía la reelección inmediata de los legisladores, daría lugar a unas élites legislativas más especializadas y que con ello aumentaría la productividad parlamentaria ${ }^{101}$.

En Estados Unidos, CLUCAS concluye que en la nueva era política, bajo los term limits, el parlamento de California ha aprobado legislación de forma más lenta de lo que era común en el pasado, y ha tenido más dificultad para aprobar el presupuesto ${ }^{102}$.

\section{IV.3. Posibles soluciones a la inexperiencia de los parlamentarios y a la debilidad del parlamento frente al gobierno}

La reelección no garantiza por sí misma el saber ni la experiencia de los legisladores sobre los asuntos parlamentarios ${ }^{103}$. Además, los parlamentarios "profesionales» (por el largo tiempo dedicado a esa actividad) no son expertos, ni mucho menos, en cada una de las áreas en que se despliega la política. En muchos casos necesitan el asesoramiento de verdaderos expertos, y en esto no se diferencian de los políticos aficionados, elegidos para un solo mandato.

${ }^{99}$ CARESS, Stanley M. and KUNIOKA, Todd T.; Term limits and Their Consequence..., op. cit., pág. 176.

${ }^{100}$ CAREY, John M.; Richard G. NIEMI and Linda W. POWELL. Term limits in the state legislature, op. cit., pág. 128.

101 TOVAR MENDOZA, Jesús. «Condicionantes políticos...», op. cit. pág. 197.

102 CLUCAS, Richard A.. "California: The New Amateur Politics», op. cit., pág. 25.

${ }^{103}$ En ese sentido, MEDINA PÉREZ, Alejandro. "Breves apuntes respecto al principio de la no reelección en México», Letras Jurídicas, Revista electrónica de Derecho del Centro Universitario de la Ciénaga, Otoño, Septiembre 2006- Marzo 2007, Núm. 3 , págs. 1-19, esp. págs. 14 y 16, DWORAK, Fernando. El legislador a examen, el debate sobre la reelección en México, México, Fondo de Cultura Económica- Cámara de Diputados, 2002, pág. 15; ANDREA SÁNCHEZ, Francisco José de. «Reelección legislativa consecutiva...», op. cit., pág. 304. 
Dicho esto, frente a la inexperiencia de los parlamentarios se han propuesto diversas medidas. Una de ellas es suprimir o flexibilizar las limitaciones de mandato ${ }^{104}$. De hecho, en Méjico se ha sustituido la no reelección consecutiva de los parlamentarios por una reelección consecutiva limitada a un máximo de doce años en cada cámara. Sin embargo, en Estados Unidos, como en la mayoría de los estados federados que han adoptado los term limits los votantes no manifiestan su voluntad de suprimirlos o flexibilizarlos -antes al contrario ${ }^{105}$-, la medida más eficaz que se ha adoptado consiste en instruir a los nuevos legisladores en la organización y funcionamiento de las cámaras y en el trabajo parlamentario ${ }^{106}$.

En la obra de KURTZ, CAIN y NIEMI ${ }^{107}$ se comprueba que varios estados, como Georgia, han adoptado programas de instrucción diseñados para educar a los legisladores y personal en políticas y procedimientos. Otros estados, como Florida, han encontrado vías para facilitar y regularizar la transición de liderazgo, teniendo miembros incluso como vicepresidentes de las comisiones.

En cambio, en Méjico, bajo el sistema de no reelección consecutiva, se han pagado dietas muy elevadas a los parlamentarios para que aprendan su función, lo que ha producido las críticas de la opinión pública. Por esta razón, MEDINA PÉREZ propone que la formación de los futuros parlamentarios corra a cargo de los partidos políti$\cos ^{108}$.

Por otro lado, la debilidad del parlamento frente al gobierno no se puede achacar, sin más, a la inexperiencia de los parlamentarios o a las limitaciones de mandato (pues tan bien se da en países que carecen de esta institución), sino que depende de muchos otros factores:

${ }^{104}$ Así, por ejemplo en el estudio de SARBAUGH-THOMPSON, Marjorie; LYKE THOMPSON, Charles D. ELDER, John STRATE, and Richard C. ELLING. Political and Institutional Effects of Term limits, op. cit., pág. 198, se propone incrementar la duración de los term limits a 12 años en cada cámara.

${ }^{105}$ Por ejemplo, en Montana y Arkansas, en 2004, los ciudadanos rechazaron en votación popular sendos intentos de suprimir los térm limits. Un nuevo intento contra los term limits se ha producido en Missouri en enero de 2014. Mientras tanto, en Maryland y en Illinois continúa la batalla por introducir las limitaciones de mandato en 2014. Todos estos casos pueden verse en: https://termlimits.org/term-limits/stateterm-limits/current-battles/, y en sus correspondientes enlaces (Páginas visitadas el 20 de junio de 2014).

${ }^{106}$ En este sentido, CAIN, Bruce E.. Adapting to term limits, op. cit. pág. 99; KURTZ, Karl T.; CAIN, Bruce E.; NIEMI, Richard G. (Eds.). Institutional Change in American Politics..., op. cit. pág. 192.

${ }^{107}$ KURTZ, Karl T.; CAIN, Bruce E.; NIEMI, Richard G. (Eds.). Institutional Change in American Politics..., op. cit. págs. 192 y 193.

${ }^{108}$ MEDINA PÉREZ, Alejandro. "Breves apuntes...», op. cit., pág. 15. 
la forma de gobierno (presidencial o parlamentaria); el sistema electoral, en especial si es mayoritario o proporcional; la organización interna de partidos políticos, y en especial la disciplina de voto en el interior de los partidos.

No se pueden extrapolar a España (régimen parlamentario) las conclusiones extraídas de EE.UU. o Méjico (regímenes presidencialistas), en cuanto al control parlamentario del gobierno en un sistema bajo term limits.

Asimismo, influye mucho el sistema electoral, según sea proporcional o mayoritario. En un sistema proporcional, habrá, en principio, y como tendencia general ${ }^{109}$, más partidos presentes en el parlamento, lo que permitirá más opciones en la discusión de los asuntos públicos y, en consecuencia, aumentarán las posibilidades de control del parlamento sobre el gobierno.

Esto lo prueba claramente el caso de Méjico, donde, mientras se ha mantenido el principio de prohibición de la reelección inmediata de los legisladores, las sucesivas reformas electorales en un sentido cada vez más proporcional, han incrementado la competencia partidaria y el pluralismo legislativo, y han determinado que los parlamentos hayan sido más capaces de controlar el poder ejecutivo ${ }^{110}$ y el gasto público ${ }^{111}$.

También debe tenerse en cuenta la organización intrapartidaria y la disciplina de partido en las relaciones entre gobierno y parlamento.

${ }^{109}$ DUVERGER, Maurice. Los partidos políticos, Fondo de Cultura Económica de España, Madrid, 2002 (Original en francés de 1951).

${ }^{110}$ En este sentido, véase BEER, C. Electoral Competition and Institutional Change in Mexico, Notre Dame: University of Notre Dame Press, 2003, SOLT, F.; «Electoral Competition, Legislative Pluralism and Institutional Development: Evidence from Mexico's States", en Latin American Research Review, vol. 39, núm.1, 2004, págs.155-167.

${ }^{111}$ Véase GUILLÉN LÓPEZ, T. «Gobierno dividido en Baja California: integración y dinámica legislativa en el periodo 1989-1995», en Alonso LUJAMBIO (editor). Gobiernos divididos en la federación mexicana, México: Universidad Autónoma Metropolitana/ Instituto Federal Electoral / Colegio Nacional de Ciencias Políticas y Administración Pública, 1996, págs. 33-68, RIONDA, L. M. «Guanajuato: gobierno dividido y cohabitación partidista, 1991-1996», en Alonso LUJAMBIO (editor). Gobiernos divididos en la federación mexicana, México: Universidad Autónoma Metropolitana/ Instituto Federal Electoral/ Colegio Nacional de Ciencias Políticas y Administración Pública, 1996, págs. 69-97, AZIZ NASSIF, A. «Gobiernos divididos: entre la reforma y la polarización», en María Amparo CASAR e Ignacio MARVÁN (coords.). Gobernar sin mayoría, México: Taurus/ Centro de Investigación y Docencia Económicas, 2002, págs. 295-317. En cambio, PÉREZ VEGA considera que estas reformas electorales han sido necesarias pero no suficientes para convertir a los parlamentos en instituciones efectivas de control y supervisión horizontal- PÉREZ VEGA, MOISÉS; «La debilidad institucional de los congresos locales...», op. cit. pág. 259. 
En países como Méjico y España, en los que el Jefe de Gobierno suele ser, a su vez, el líder del partido que tiene mayoría en el parlamento, es el gobierno el que a través de la dirección del partido mayoritario controla al parlamento, y no al revés. Y esto se da con independencia de si existen limitaciones de mandato (Méjico) o no (España), o de si el régimen político es parlamentario o presidencial.

En consecuencia, hay medidas más eficaces que la supresión de la limitación de mandatos para restablecer la primacía del parlamento sobre el gobierno. Por ejemplo, establecer un sistema de incompatibilidades que prohíba a los miembros del gobierno asumir ningún cargo directivo en el partido. Esto impediría, o dificultaría, que el gobierno controlara el parlamento a través de la dirección del partido mayoritario.

También fortalecería al parlamento, en relación con el poder ejecutivo y con la dirección de los partidos políticos, una democratización profunda de éstos, de modo que los futuros candidatos parlamentarios no fueran designados por los cargos directivos del partido, sino por los militantes (por ejemplo, en elecciones primarias). A su vez, la dirección del partido debería ser elegida democráticamente por todos los militantes.

\section{IV.4. Otro posible inconveniente: se impone una visión cortoplacista de la política}

Se considera que la limitación de mandatos impide realizar proyectos a largo plazo ${ }^{112}$. O que estimula a los legisladores a optar por soluciones de breve plazo o por soluciones rápidas, mientras que las soluciones más difíciles son dejadas para el largo plazo ${ }^{113}$.

Sin embargo, esto inconveniente también se da en países donde no existe limitación de mandatos, y depende del hecho de que la duración de los mandatos parlamentarios es relativamente breve (un máximo de cuatro o cinco años) como una forma de control popular de los representantes electos. De hecho, se puede establecer la siguiente ecuación: cuando más breves sean los mandatos parlamenta-

112 NOHLEN, Dieter. "XV. La reelección», op. cit. pág. 292.

113 Opinión recogida en KURTZ, Karl T.; CAIN, Bruce E.; NIEMI, Richard G. (Eds.). Institutional Change in American Politics..., op. cit. pág. 18. 
rios, es decir, cuanto más frecuentes sean las elecciones, mayor control popular del poder político ${ }^{114}$.

De todas formas, a pesar de que se turnen las personas en el ejercicio del poder, esto no impide que los partidos políticos puedan mantener proyectos a largo plazo.

No obstante, en la práctica no se han encontrado evidencias sustantivas de que este supuesto inconveniente de la limitación de mandatos sea cierto ${ }^{115}$.

\section{IV.5. El problema de la rendición de cuentas}

Se considera que con la limitación de mandatos se reducen las posibilidades de exigencia de responsabilidad política de los cargos electos ante los electores. Dirá NOHLEN:

«La no reelección restringe la capacidad del electorado de enjuiciar -positiva o negativamente- a los representantes. En términos generales, mediante la no reelección se garantiza la alternancia personal en el mandato, sin que ésta tenga algún efecto de control sobre su ejercicio. En la teoría democrática se le atribuye tal efecto de control a las elecciones en caso de que el diputado en ejercicio se vuelva a presentar como candidato». ${ }^{116}$

Por su parte, AZIZ opina que: «Lo que sí propicia la reelección es que los legisladores cuiden a sus electores, porque de ellos depende su posibilidad de continuar en el cargo» ${ }^{117}$.

Nótese que el control por parte de los electores sólo se produciría en el supuesto de que el parlamentario optase por volver a presentarse a las elecciones. Y que dicho control consiste, exclusivamente, en la posibilidad de volver a elegirlo o no.

${ }^{114}$ Ya a mediados del siglo XIX, Alexis de TOCQUEVILLE había subrayado la importancia de la frecuencia de las elecciones para el gobierno democrático del pueblo. Véase: TOCQUEVILLE, Alexis de. La democracia en América, Fondo De Cultura Económica, México, 1978, pág. 191.

${ }^{115}$ KURTZ, Karl T.; CAIN, Bruce E.; NIEMI, Richard G. (Eds.). Institutional Change in American Politics..., op. cit. pág. 192.

${ }^{116}$ NOHLEN, DIETER; «XV. La reelección», op. cit., págs. 292 y 293.

117 AZIZ NASSIF, A. "Las Reformas Pendientes de una Democracia Todavía Débil», en Liminar, Estudios Sociales y Humanísticos, junio, año/vol. IV, núm. 001, México: Universidad de Ciencias y Arte de Chiapas, San Cristóbal de las Casas, 2006, pág. 10. En el mismo sentido, TOVAR MENDOZA, Jesús. "Condicionantes políticos...», op. cit. pág. 195, JAIMES DELGADO, David Alberto. "¿Cómo fortalecer ...?», op. cit. págs. 73 y 81 . 
Se supone que si el parlamentario aspira a ser reelegido, intentará una conducta más responsable hacia los electores, de cara a una futura reelección. Si no piensa presentarse a la reelección, actuará más libremente, sin tener en cuenta las preferencias de los electores.

Pero este silogismo sólo funcionaría en determinadas condiciones, que no se dan en todos los países, ni mucho menos: primero, un sistema electoral mayoritario, con circunscripciones electorales uninominales, que permitan asegurar la responsabilidad del diputado frente a los electores de su distrito. Y segundo, una organización partidaria que no cuente con una fuerte disciplina de voto. Estas condiciones se dan en Estados Unidos. En este caso, la posibilidad de reelección del candidato, o de continuar su carrera profesional ocupando cargos de naturaleza electiva, no depende del partido, sino del propio candidato y, en principio, de los electores de su distrito. Ahora bien, en la práctica, el sistema electoral en Estados Unidos queda distorsionado por la casi ausencia de límites legales a la financiación privada de las campañas electorales (sobre todo, a raíz de la polémica Sentencia del Tribunal Supremo Federal, en el caso Citizens United v. Federal Electoral Commission, de 21 de enero de $2010^{118}$ ), donde cobran un papel muy relevante los grupos de presión.

En Estados Unidos, el candidato sujeto a limitación de mandatos es en teoría más libre a la hora de rendir cuentas a su electorado (pues no volverá a ser reelegido). Pero lo mismo sucedería si existiera el mecanismo de la reelección, y el parlamentario optase por no presentarse a la reelección. En todo caso, operará el mecanismo de rendición de cuentas ante el electorado si pretende continuar con su carrera política, postulándose para otros cargos electivos.

Sin embargo, si no se dan las condiciones que hemos visto (sistema electoral mayoritario con circunscripciones uninominales y organización partidaria sin una fuerte disciplina de voto), el diputado, para su reelección, no dependerá tanto de la voluntad de los lectores como de la voluntad del partido de designarlo como candidato. Esto es lo que pasa en Méjico y en España.

En Méjico, el sistema electoral es mixto: en parte proporcional y en parte mayoritario, como hemos visto. Pero, aunque sólo se tuvie-

${ }^{118}$ Véase al respecto ROALES, Oliver. «La desregulación de la financiación electoral por el Tribunal Supremo estadounidense y el riesgo de privatización de la representación política», Jueces para la democracia, N. ${ }^{\circ}$ 72, 2011, págs. 24-32, VALERO HEREDIA, Ana. «Citizens United y la financiación de las campañas electorales en el Derecho norteamericano», UNED. Teoría y Realidad Constitucional, núm. 30, 2012, págs. 433-453. 
ran en cuenta los distritos uninominales, el diputado depende más del partido que de los electores de su distrito: primero, es el partido el que decide quiénes se presentarán como candidatos a la votación por los electores ${ }^{119}$; segundo, es el partido el que lleva la financiación de la campaña electoral, y no los candidatos individuales; tercero, en el funcionamiento parlamentario, los líderes del correspondiente grupo parlamentario tienen el peso en la toma de decisiones y los parlamentarios están obligados a cumplir la disciplina de voto de su partido, por lo que mal pueden actuar libremente para satisfacer las demandas de los electores de su distrito ${ }^{120}$.

Esta situación no cambia porque se suprima la limitación de mandatos consecutiva (prohibición de reelección para el período inmediatamente posterior), y se sustituya por reelección inmediata con un límite de doce años (cuatro mandatos de tres años en la cámara de diputados, y dos mandatos de seis años en el senado), como rige ahora en Méjico, o incluso por una reelección inmediata ilimitada.

El problema de la falta de responsabilidad de los parlamentarios ante sus electores no está en la limitación de mandatos, como se ha querido ver en Méjico ${ }^{121}$, sino en la dependencia del parlamentario respecto de su partido.

En España, donde el sistema electoral es proporcional y las circunscripciones son plurinominales, la situación es similar: el parlamentario depende completamente del partido en el momento de presentarse como candidato, en el de la financiación de la campaña electoral, y en el del voto en el parlamento.

En realidad, en este sistema sigue operando la responsabilidad de los parlamentarios ante los electores, pero de una manera mediata: el parlamentario es responsable ante su partido, y su partido lo es ante los electores ${ }^{122}$. Pero la responsabilidad no ha sido suprimida, ni será suprimida, por la limitación de mandatos. La rendición de cuentas

${ }^{119}$ Señala esta dependencia en el momento de la presentación de las candidaturas: LUJAMBIO, Alonso. «La Reelección de los Legisladores...», op. cit. pág. 195.

${ }^{120}$ Esta situación de dependencia del parlamentario respecto del partido, en los tres aspectos mencionados, es reconocida, para el caso de Méjico, por JAIMES DELGADO, David Alberto. “¿Cómo fortalecer ....?», op. cit. pág. 92.

${ }^{121}$ Así lo ha querido ver, entre otros, PÉREZ VEGA, MOISÉS; "La debilidad institucional de los congresos locales...», op. cit. pág. 265, donde se dice que «la prohibición de reelección legislativa inmediata, al generar la rotación total de los cargos legislativos cada tres años, otorga a las dirigencias partidistas un gran poder para la distribución de candidaturas».

${ }^{122}$ En este sentido, NACIF, Benito. La no reelección consecutiva..., op. cit. pág. 17, PÉREZ VEGA, MOISÉS; "La debilidad institucional de los congresos locales...», op. cit. pág. 265. 
del parlamentario se realiza ante el partido, tanto si es reelegido como si no. Si existe prohibición de reelección y el diputado ha agotado su mandato, pero quiere continuar su carrera política postulándose para otros cargos electivos, seguirá rindiendo cuentas ante el partido. Entonces, es el partido el que rinde cuentas ante el electorado por el comportamiento de los diputados que él incluyó en las listas electorales (abiertas o cerradas), al confeccionar las candidaturas.

\section{OBSTÁCULOS JURÍDICOS Y POLÍTICOS PARA EL ESTABLECIMIENTO DE LA LIMITACIÓN DE MANDATOS}

\section{V.1. Obstáculos jurídicos: el derecho de sufragio}

Se ha argumentado que la limitación de mandatos restringe el derecho del elector de votar libremente por candidatos de su preferencia, «derecho que se limita legítimamente sólo por consideraciones funcionales a la democracia» ${ }^{123}$.

Se trata de un argumento bastante débil, pues el elector no tiene un derecho ilimitado a elegir a quien quiera como parlamentario. Sólo podrá elegir entre aquellos candidatos que hayan presentado su candidatura de acuerdo con la legislación electoral. Y uno de los requisitos para presentarse como candidato es no incurrir en causa de inelegibilidad. La limitación de mandatos se configuraría en nuestro país como una causa de inelegibilidad ${ }^{124}$.

En España resultaría cuando menos irónico defender el argumento del derecho de los ciudadanos a votar a los candidatos de su preferencia contra la limitación de mandatos, cuando, en la mayoría de las elecciones, las listas electorales son cerradas y bloqueadas (impuestas en ocasiones por la dirección del partido, que es la que confecciona las candidaturas). Aunque las listas se tornaran abiertas, las circunscripciones plurinominales, con gran número de candidatos procedentes de diversas formaciones políticas, dificultarían enormemente que los votantes llegaran a conocerlos ${ }^{125}$.

${ }^{123}$ NOHLEN, Dieter. «XV. La reelección», op. cit. pág. 290.

${ }^{124}$ En este sentido, Eloy GARCÍA considera la irreelegibilidad como un supuesto concreto de inelegibilidad- GARCÍA, Eloy. «Irreelegibilidad, inelegibilidad e incompatibilidad parlamentaria: Los artículos 23 y 70 de la Constitución y las razones políticas de la prohibición de ser reelegido», en ASAMBLEA Revista Parlamentaria de la Asamblea de Madrid, núm. 14, junio 2006, págs. 3-21, esp. págs. 19 y ss.

${ }^{125}$ No obstante, sobre la necesidad jurídica de desbloquear el voto en España, véase IBÁÑEZ MACÍAS, Antonio. «El voto desbloqueado: una exigencia constitucio- 
En Estados Unidos las limitaciones de mandato han sido declaradas inconstitucionales en algunos supuestos. En tres estados -Massachusetts (medida adoptada en 1994 y declarada inconstitucional en 1997), Washington (1992 y 1998 respectivamente) y Wyoming (1992 y 2004 respectivamente)-, en los que los límites de mandato fueron establecidos vía iniciativa legislativa popular, los tribunales supremos estatales declararon que las limitaciones de mandato constituían un requisito adicional para los cargos públicos y que, en consecuencia, sólo podían ser establecidas por la Constitución y no por las leyes. En Oregón, el Tribunal Supremo declaró inconstitucionales, en 2002, los term limits, adoptados en 1992, por un motivo diferente: una iniciativa popular no puede contener más de una materia ${ }^{126}$.

Asimismo, los intentos de las estados federados de establecer limitaciones de mandatos a los diputados y senadores del Congreso federal elegidos por su circunscripción fueron declarados inconstitucionales por el Tribunal Supremo Federal en el caso US Term Limits, Inc. v. Thornton, 514 US 779, decidido el 22 de mayo de 1995, donde se declaró, en una decisión polémica (por cinco votos contra cuatro) que los estados federados no pueden imponer restricciones adicionales, tales como las limitaciones de mandato, a sus representantes en el gobierno federal, más allá de las previstas por la Constitución federal ${ }^{127}$.

Por otra parte, en la Constitución española de 1878 no existe, en principio, ningún precepto que prohíba la limitación de mandatos. En efecto, artículo 68.4 CE estipula que: «el Congreso es elegido por cuatro años. El mandato de los Diputados termina cuatro años después de su elección o el día de la disolución de la Cámara»; y el artículo 69.6 CE establece que «el Senado es elegido por cuatro años. El mandato de los Senadores termina cuatro años después de la elección o el día de la disolución de la Cámara». En ninguno de estos preceptos se dice nada sobre la reelección de los diputados, ni a favor de una reelección indefinida, ni en contra de la misma.

Este silencio podría interpretarse a favor de la reelección indefinida y en contra de la limitación de mandatos parlamentarios, pues ésta supone una restricción del derecho de sufragio pasivo. De aquí podría deducirse que para limitar los mandatos de los miembros de las Cos-

nal», en M. ${ }^{a}$ Isabel GARRIDO GÓMEZ y Ramón RUIZ RUIZ (Editores). Democracia, gobernanza y participación, Tirant lo Blanch, Valencia, 2014.

${ }^{126}$ Los datos pueden verse en: http://www.ncsl.org/research/about-state-legislatures/chart-of-term-limits-states.aspx (Página visitada el 23 de junio de 2014).

${ }^{127}$ La sentencia puede leerse en: http://laws.findlaw.com/us/514/779.html (Página visistada el 23 de junio de 2014). 
tes Generales habría que reformar la Constitución. Sin embargo, esta interpretación no es la más coherente con el texto constitucional, porque realmente el precepto a tener en cuenta es el artículo $70.1 \mathrm{CE}$, el cual dispone que «la ley electoral determinará las causas de inelegibilidad e incompatibilidad de los Diputados y Senadores».

Así pues, le limitación de mandatos parlamentarios, para las Cortes Generales, puede ser establecida, como una causa de inelegibilidad, en la LOREG (Ley Orgánica 5/1985, de 19 de junio, de Régimen Electoral General). En consecuencia, no pueden establecerlas las Comunidades Autónomas, para los miembros de las Cortes Generales, ni siquiera para los denominados «senadores autonómicos» (art. 69.5 CE). Para los diputados autonómicos, la limitación de mandatos debe ser establecida por los Estatutos de Autonomía (o, por remisión de éstos, en su correspondiente ley electoral autonómica), en virtud de su competencia de autoorganización (art.148.1.1 CE), dentro del respeto de las disposiciones previstas por la LOREG sobre causas generales de inelegibilidad $^{128}$. En cambio, en virtud de la reserva a ley orgánica del régimen electoral general (art. 81.1 CE), para los concejales la limitación de mandatos debe ser establecida en la LOREG (o preferiblemente en la Constitución, en una hipotética reforma constitucional $)^{129}$, y no en la Ley que regula las bases del régimen local (Ley 7/1985, de 2 de abril), en aplicación del artículo 149.1.18. ${ }^{\mathrm{a}} \mathrm{CE}$.

Debe entenderse que la limitación de mandatos es una restricción del derecho de sufragio pasivo, pero que en ningún caso entraña una negación del mismo. Sólo una limitación de mandatos total (para cualquier cargo público electivo) y absoluta (de por vida), supondría en lo sucesivo una negación del derecho de sufragio pasivo para la persona que incurriera en la misma. Si la limitación de mandatos fuese total pero consecutiva, limitaría el derecho de sufragio pasivo de forma intermitente, que podría ejercerse transcurrido el tiempo estipulado. Si la limitación de mandatos fuese parcial (para un determinado cargo público, ejemplo diputado o senador) y de por vida, nada impediría a la persona afectada presentarse como candidato para otros cargos públicos electivos. Por último, si, como es frecuente, la limitación de mandatos fuese parcial y consecutiva, la persona afectada podría presentarse como candidato al cargo público concernido, transcurrido el tiempo prescrito, y además, a cualquier otro cargo público electivo.

\footnotetext{
${ }^{128}$ Véase la Disposición Adicional Primera de la LOREG.

${ }^{129}$ Las causas específicas de inelegibilidad de los concejales se regulan, actualmente, en el artículo 177.2 LOREG.
} 
La limitación de mandatos afectaría al derecho de sufragio activo, pero más directamente al derecho de sufragio pasivo de los ciudadanos, y vendría justificada por consideraciones muy importantes para el buen funcionamiento de la democracia: el mayor reparto del poder político, la renovación de las élites políticas, la prevención del clientelismo político y de la corrupción. Precisamente la limitación de mandatos puede entenderse como una limitación del derecho sufragio pasivo para, en la práctica, ampliar este mismo derecho, de manera efectiva, a un mayor número de personas, como una medida tendente a «facilitar la participación de todos los ciudadanos en la vida política» y a remover los obstáculos que impidan o dificulten la igualdad real y efectiva en el ejercicio del derecho fundamental a participar en los asuntos públicos (art. 9.2 CE, en relación con el art. 23 CE).

La limitación de mandatos parlamentarios, como límite del derecho de sufragio pasivo, también halla su fundamento como garantía de la libertad de ejercicio del derecho de sufragio activo ${ }^{130}$, al evitar que la perpetuación de las mismas personas en el ejercicio del poder pueda dar lugar a una clase política cerrada que se autopostule a sí misma (mediante la confección de las lista electorales por la dirección de los partidos), e impida, mediante una serie de ventajas competitivas (normas electorales, etc), que otros ciudadanos puedan alcanzar el poder presentándose a las elecciones.

Esta media podría ser adoptada por ley orgánica, con lo que sólo necesitaría mayoría absoluta del Pleno del Congreso de los Diputados. Pero precisamente ahí estaría su talón de Aquiles. Para evitar que la medida quedara al albur de futuras mayorías parlamentarias, sería conveniente introducirla en la Constitución, mediante reforma constitucional del artículo 70.1 CE por mayoría de tres quintos. De esta forma se garantiza su supervivencia por largo tiempo, como ha sucedido en los estados federados norteamericanos y en Méjico.

\section{V.2. Obstáculos políticos: la tendencia general de los gobernantes a perpetuarse en el ejercicio del poder}

La limitación de mandatos se contrapone a la tendencia general de los gobernantes a perpetuarse en el ejercicio del poder. Por lo que, de entrada, tiene en contra prácticamente a toda la clase política, especialmente a los titulares de cargos públicos electivos afectados y a

${ }^{130}$ Este es el fundamento de las causas de inelegibilidad para Eloy GARCÍA GARCÍA, Eloy. «Irreelegibilidad, inelegibilidad...», op. cit., págs. 14, 15 y 19-. 
los aspirantes a los mismos. La contraposición será mayor cuanto más profesionalizada esté la clase política.

¿Cómo ha sido posible entonces que los term limits se hayan constitucionalizado en algunos países?

Este hecho raro, por escaso, puede tener diversas explicaciones. O bien, en el momento de establecer las limitaciones de mandato, se ha producido un vacío de poder, como consecuencia de una guerra o una revolución, y no ha dado tiempo a que se formara una clase política consolidada (Constitución francesa de 1791, Constitución española de 1812), o bien la clase política no estaba suficientemente profesionalizada, y no tenía mucho que perder (Méjico en 1933), o bien la medida ha sido impuesta por los ciudadanos a una clase política profesionalizada y reticente (algunos estados federados de los Estados Unidos, a partir de 1990) mediante una avanzada institución de democracia semidirecta.

En España los ciudadanos no cuentan con la poderosa institución de la iniciativa popular de reforma constitucional, tal como se configura en algunos estados norteamericanos, por lo que no podrían establecer la limitación de mandatos a nivel constitucional, en contra de la voluntad parlamentaria, aunque tuvieran a su favor la mayoría de la opinión pública. Introducir tal institución de democracia semidirecta a nivel constitucional plantearía casi las mismas dificultades que implica el establecimiento de los term limits. El artículo $166 \mathrm{CE}$ no permite la iniciativa popular de reforma constitucional. Tampoco sería posible, mediante iniciativa legislativa popular, modificar la ley electoral para implantar los term limits, pues el artículo 87.3 CE lo prohíbe, al ser una materia reservada a ley orgánica (art. 81.1 CE). Además, a diferencia de muchos estados federados norteamericanos, en España la iniciativa legislativa popular no se puede imponer, mediante votación popular, contra la voluntad del parlamento.

En Francia y en España la medida se introdujo en sendos momentos constituyentes revolucionarios (Constituciones de 1791 y de 1812, respectivamente) es decir, antes de que se consolidara la clase política. La experiencia no volvió a repetirse en sucesivos períodos constituyentes ${ }^{131}$.

${ }^{131}$ El hecho de que la limitación de mandatos no volviera a darse en el constitucionalismo francés, ni español, pudo deberse a que lo impidió la nueva clase política, ya consolidada. También pudo deberse, sencillamente, a que no se consideró necesario introducir tal medida, al no existir todavía la figura del político profesional (al menos durante buena parte del siglo XIX). Pero para confirmar cualquiera de estas 
En el caso de la reforma constitucional mejicana de 1933, la clase política no estaba profesionalizada. En efecto, de acuerdo con los datos aportados por JOSÉ VALENZUELA, antes de la reforma de 1933, en el intervalo de 1917 a 1924, en la Cámara de Diputados, de 2414 diputados federales, propietarios y suplentes, se reeligieron 316, es decir el 13,09 por ciento ${ }^{132}$. Asimismo, Rogelio HERNÁNDEZ subraya que de 1917 a 1940 el 75 por ciento de los diputados ocuparon el escaño sólo una vez ${ }^{133}$. A pesar de esto, cabría preguntarse, con ANAYA, «¿cómo fue que los diputados aceptaron una propuesta de reforma que lesionaba sus propios intereses?»134. Después de examinar las explicaciones de otros estudiosos, ANAYA parece encontrar una respuesta, que se antoja convincente, en la partitocracia ya entonces existente, que hacía depender del partido (de su comité ejecutivo), y no de los electores, al parlamentario: «Como el enjuiciamiento de su labor no dependía del electorado, sino del partido que lo había postulado (y que podría o no volver a hacerlo), el diputado o senador preferiría disciplinar sus decisiones a las de su partido y no moldearlas de acuerdo con las peticiones ciudadanas» ${ }^{135}$.

En definitiva, cabría preguntarse si, para volver a introducir la limitación de mandatos en España, debería darse una situación similar a los procesos constituyentes de Cádiz en 1812 y de Francia en 1791, o similar a la reforma constitucional de Méjico en 1933. En lo que aquí interesa, la similitud estaría, junto a la voluntad de cambio institucional, en la existencia de un parlamento compuesto, en su inmensa mayoría, por políticos no profesionales. Tal posibilidad, aunque paradójica como condición previa para el establecimiento de la limitación de mandatos, no es del todo improbable.

hipótesis habría que realizar un estudio histórico de la limitación de mandatos y de su abandono en ambos países, lo que va más allá del propósito de este trabajo.

132 JOSÉ VALENZUELA, Gorgette Emilia. «Reelección en la Cámara de Diputados Federal de 1916 a 1924», en ESPINOZA TOLEDO, Ricardo y WELDON, Jeffrey (coords.). Para qué sirve el Poder Legislativo, México, UAM-Universidad de ColimaMiguel Ángel Porrúa, págs. 413-422., citado por CORTEZ SALINAS, Josafat. «La propuesta de la reelección inmediata...», op. cit. pág.1324.

${ }_{133}$ HERNÁNDEZ, Rogelio (2001). «La participación de los diputados en una época de reelección», en GIL VILLEGAS, Francisco y HERNÁNDEZ, Rogelio (coords.). Los legisladores ante las reformas políticas de México, México, Colmex., citado por CORTEZ SALINAS, Josafat. "La propuesta de la reelección inmediata...», op. cit. Pág.1324-1325.

134 ANAYA, Luis. «Experiencias políticas e imaginarios sociales...», op. cit. pág. 377.

135 ANAYA, Luis. «Experiencias políticas e imaginarios sociales...», op. cit. pág. 386. 


\section{A MODO DE CONCLUSIÓN. SOBRE LA EFICACIA DE LA LIMITACIÓN DE MANDATOS}

Hemos visto que en los estudios realizados en Estados Unidos se constata que la limitación de mandatos parlamentarios ha producido una efectiva renovación de los diputados y senadores estatales. Sin embargo, no ha conseguido la finalidad más ambiciosa de acabar con los políticos profesionales y sustituirlos por ciudadanos que ocasionalmente ejercen la actividad política. Ello no se ha debido a que la limitación de mandatos sea una técnica constitucional inapropiada para tal fin, sino a que la institución se ha diseñado de una manera poco estricta.

En efecto, la limitación de mandatos es una técnica susceptible de graduación, de menor a mayor intensidad, y en función de esa graduación, sus efectos sobre la renovación de las élites políticas serán menos o más intensos. La limitación de mandatos parcial (para un determinado cargo público) y consecutiva (como en Méjico antes de la reforma de 2014, o en nueve de los quince estados federados norteamericanos que disponen de esta institución), produce un efecto tímido sobre la renovación de la clase política: el político afectado, si quiere continuar con su carrera política, puede presentarse como candidato para otro cargo público electivo, antes de regresar al cargo que desempeñaba (por ejemplo, como diputado).

En la limitación de mandatos parcial y de por vida o absoluta (actualmente en Méjico tras un período de doce años en cada Cámara, y en seis estados federados norteamericanos, tras un tiempo promedio de seis u ocho años en cada una de las Cámaras): el político no puede volver al cargo que desempeñó, una vez agotado el tiempo máximo estipulado, pero puede continuar su carrera política de forma continua presentándose a otros cargos públicos electivos, en los que no exista limitación de mandatos, o hasta que se agote la limitación de mandatos establecida para esos cargos.

Ahora bien, caben otras modalidades más estrictas que no se han ensayado en Derecho comparado.

La limitación de mandatos puede ser total (para cualquier cargo público): el político afectado, una vez agotado su mandato en cualquier cargo público que haya desempeñado, no puede presentarse para ocupar ningún otro cargo público electivo (o incluso de confianza, si se quiere regular de este modo). La limitación de mandatos total puede ser, a su vez, consecutiva: el político, después de agotar el tiempo de mandato, debe volver a su actividad privada, y transcurrido un 
tiempo podrá volver a ocupar un cargo público electivo (el mismo o cualquier otro). Su carrera profesional, si existe, será intermitente en el tiempo.

Por último, la limitación de mandatos puede ser total y absoluta: una vez agotado el tiempo de mandato en un cargo público electivo, el político afectado no podrá volver a ocupar ningún otro cargo público (electivo o, si así se regula, de confianza) en su vida. En este caso no existe carrera política profesional, no existe la política como actividad profesional. Este último supuesto plantearía enormes dificultades técnicas y jurídicas: supondría una negación de por vida del derecho de sufragio pasivo, una vez que se ha ocupado un cargo público electivo, lo que resulta desproporcionado y de muy difícil justificación; además, sería imposible de realizar, por falta de "piezas de recambio», en pequeñas comunidades, donde hay pocos candidatos a elegir por tratarse de un cuerpo electoral reducido como en los pequeños o medianos municipios (o en el interior de los partidos, sindicatos o asociaciones empresariales), o por la escasa formación cívica y/o demasiada apatía política de la población. Sería, a nuestro juicio, un supuesto excesivo de limitación de mandatos.

A su vez, en un mismo ordenamiento jurídico pueden llegar a combinarse distintas modalidades de limitación de mandatos. Por ejemplo, puede ser parcial y absoluta para un determinado cargo (como el parlamentario), y a su vez total y no consecutiva para todos los demás cargos públicos electivos. La intensidad de la limitación de mandatos dependerá, en definitiva, de la finalidad que se pretenda alcanzar. 
